\title{
انتهاك مبادئ استقلالية العمل النقابي في الجزائر
}

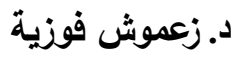

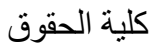 \\ جامعة الإخوة منتوري \\ قسنطينة}

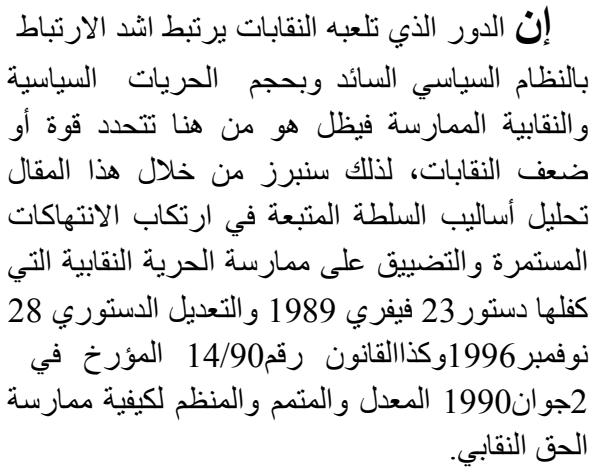


فدور النقابات ليس دور أنكميليا خاص بمعالجة بعض القضايا الاجنماعية والاقتصادية والثقافية و إنما

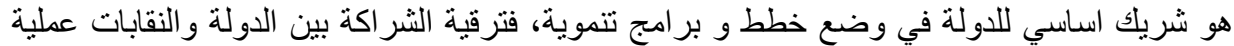

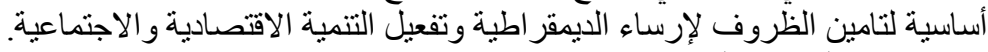

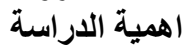

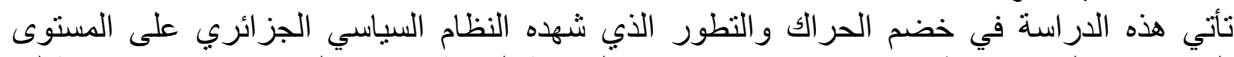

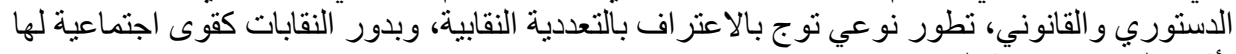

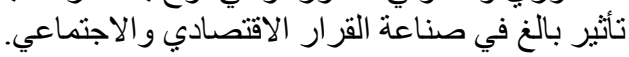

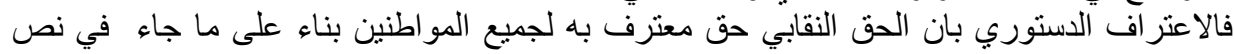

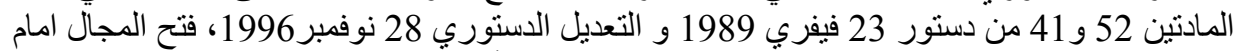

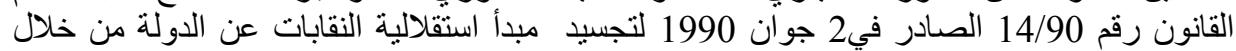

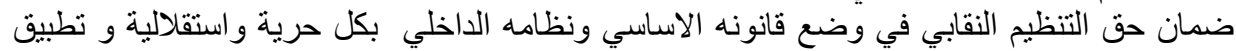

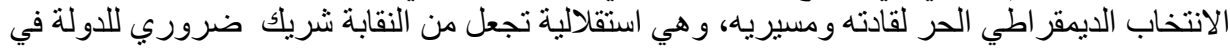
تحقيق التنمية الوطنية المستدامة.

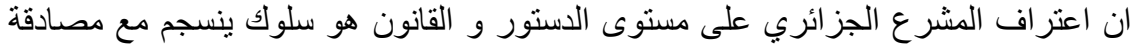

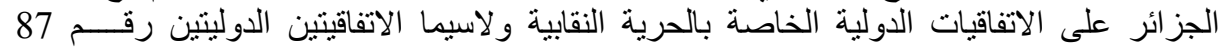

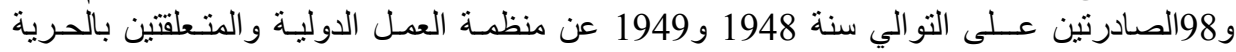

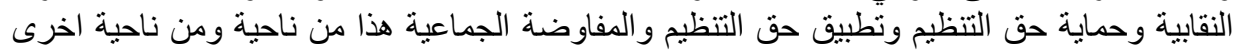

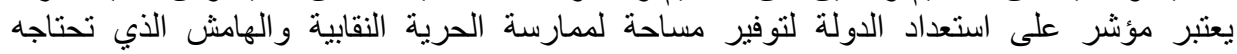

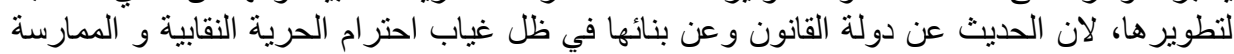

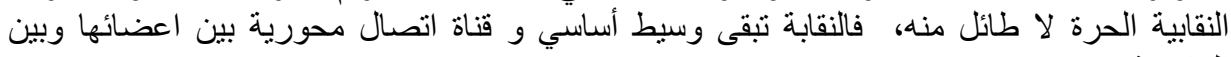

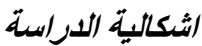

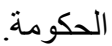

ان حصيلة التجربة النقابية الممندة لأكثر من عشريتين(1990-2015) تشير الي عدم احترام الدولة

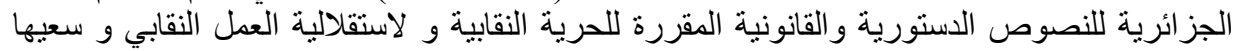

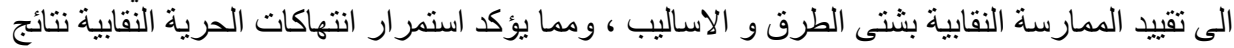

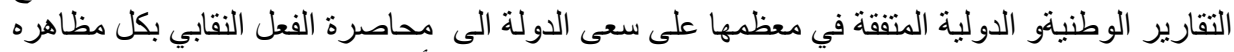

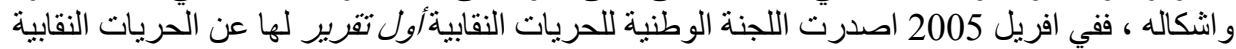

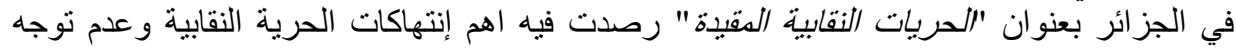

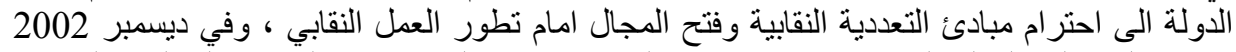

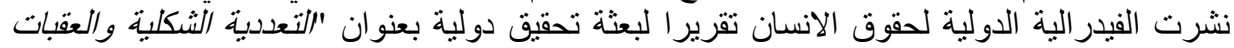

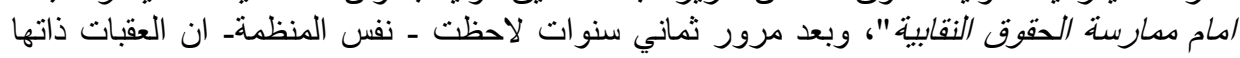
ماز الت قائمة بناء علي تقرير ها الصادر في في مأرس

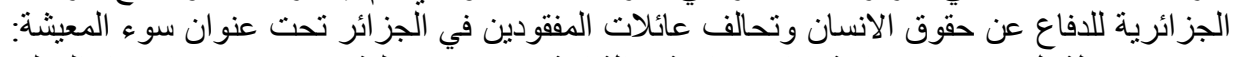

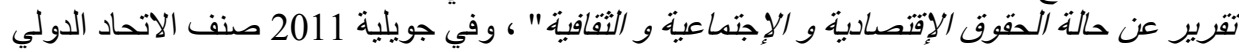

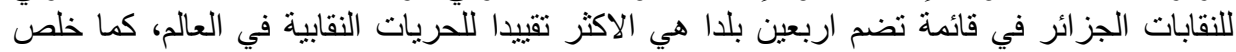

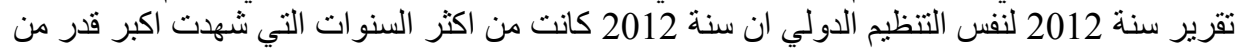

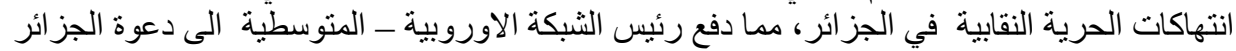

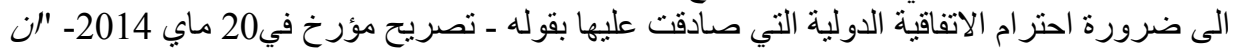

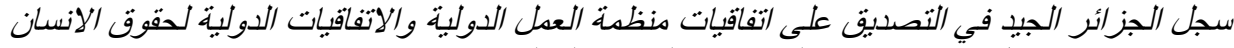
يجب ان يواكبه سجل اقوى عندما بيتعلق الامر بالتطبيق العملي". 


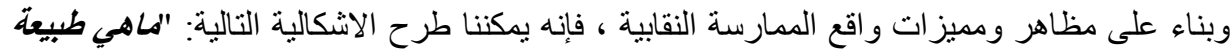

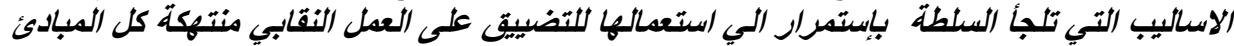

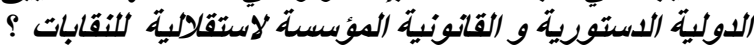
ومن اجل المعالجة العلمية لإشكالية البحث فقد قمنا بتقسيم موضوع الدراسة الى محورين

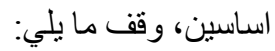

$$
\begin{aligned}
& \text { - المحور الوول:التدخل الاداري في تسيير العمل النقابي }
\end{aligned}
$$

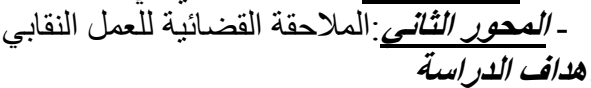

تتلخص أهداف هذه الدراسة في بيان العناصر التالية:

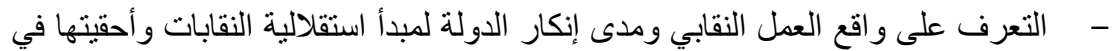

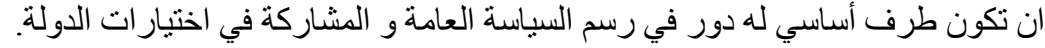

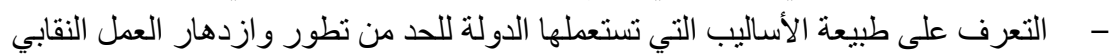

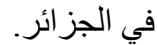

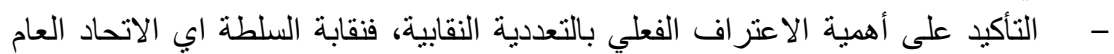

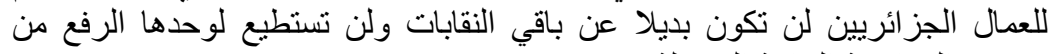
مستوى الممارسة النقابية المستقلة.

\section{اولا: التذخل الاداري في تسيير العمل النقابي}

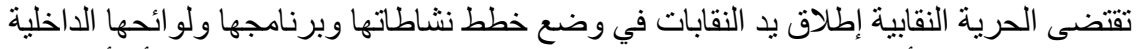

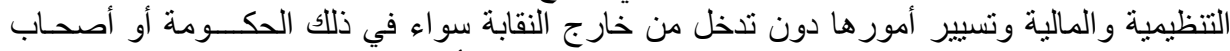

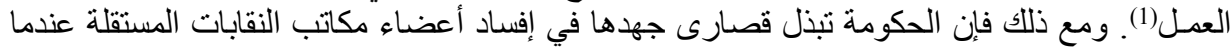

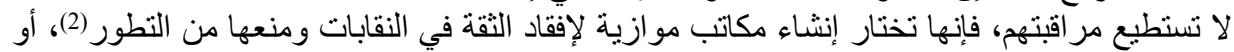

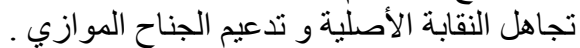

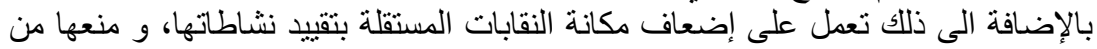

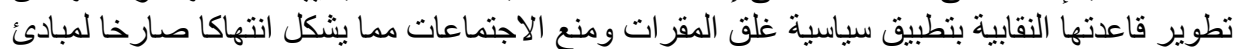

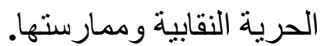

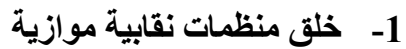

تتص المادة الخامسة عشر من القانون رقم 14/90 المؤرخ في 2 جوان فوان 1990 المحدد لكيفيات ممارسة

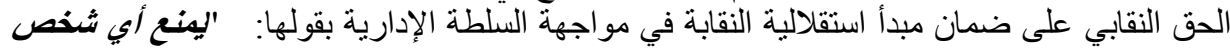

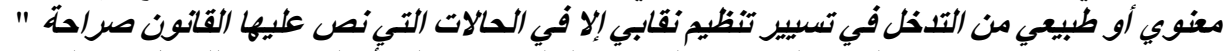

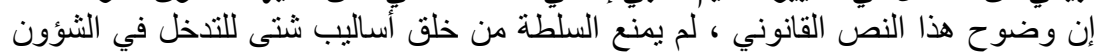

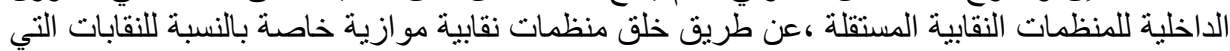

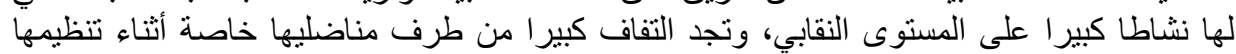

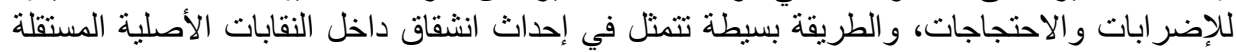
و الذي سينتج عنه سريعا انقساما ، يتم استغلاله عن طريق استخدام المناضلين الأكثر قابلية أو الأكثر

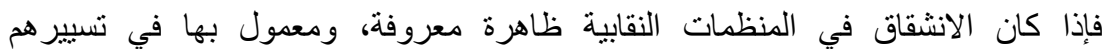
و استر اتيجيتهم فهي تغير طبيعتها إذا نم استعمالها بهدف تثويه السياسة النقابية وكل استقلالية و وليه فإن 
الممارسة المعتادة هي محاولة إظهار أن بعض المناضلين لا يو افقون على الرؤية الراديكالية لنقابتهر

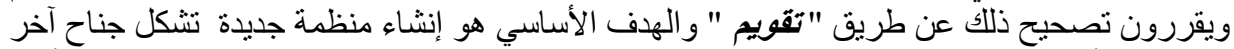

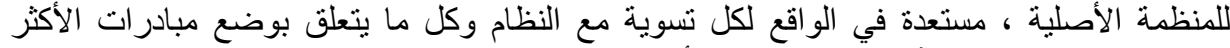

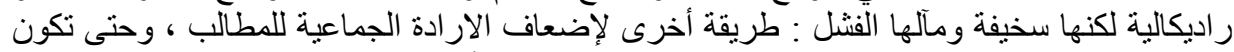

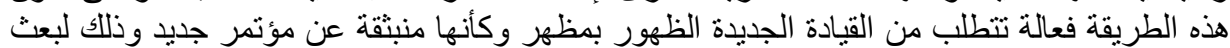

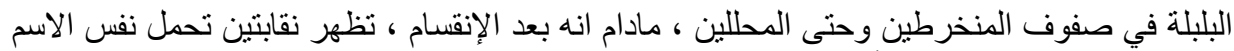

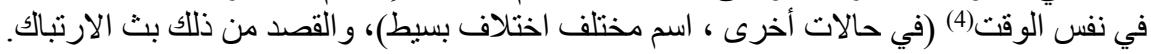

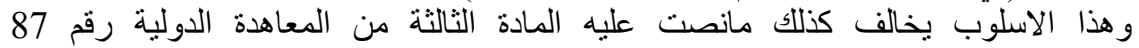

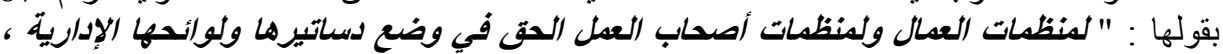

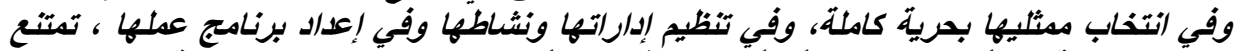

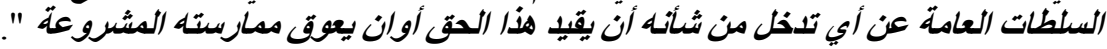

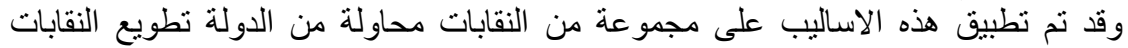

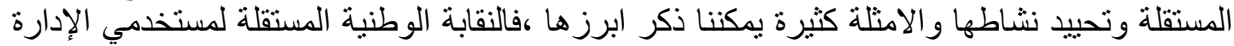

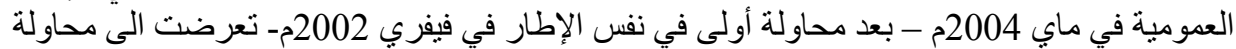

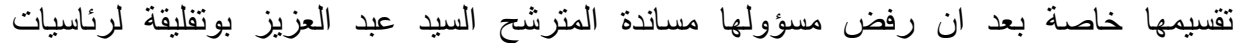

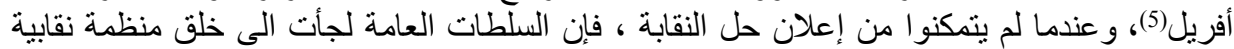

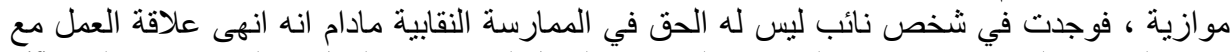

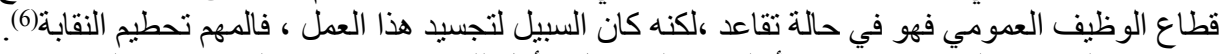

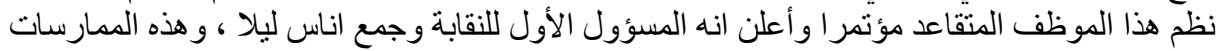

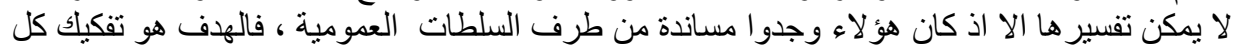

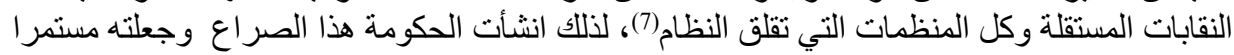

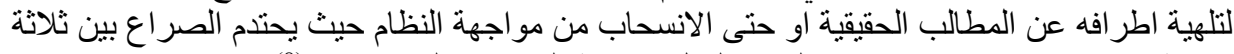

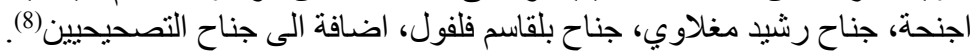

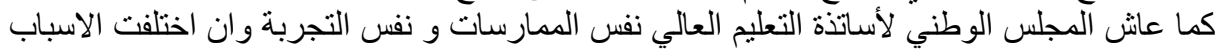

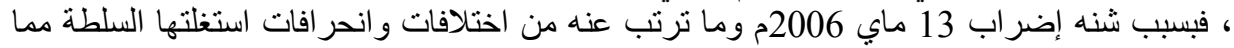
أدت في النهاية إلى تصدع النقابة من الداخل.

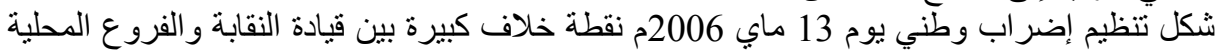

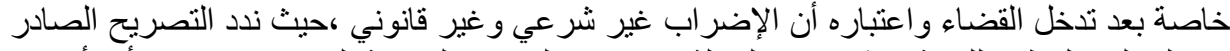

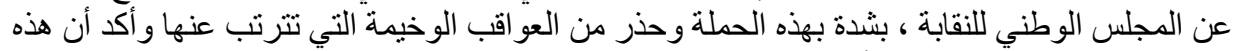

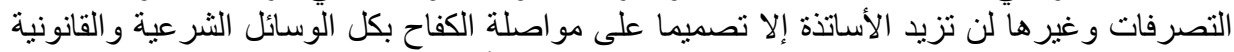

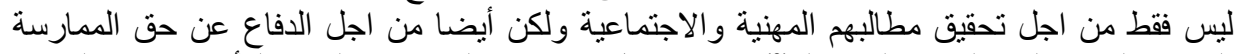

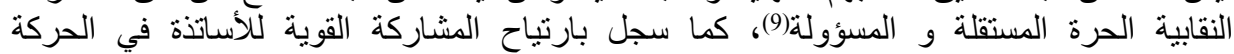

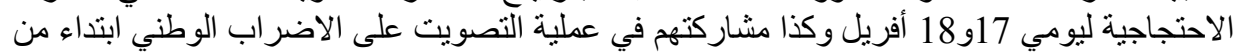

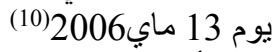
بعد أن نم الاتفاق على الدخول في إضراب وطني محدود لمدة أسبوع قرر المجلس الوطني تنظيم

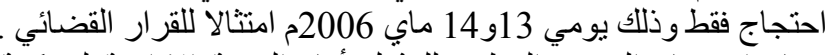

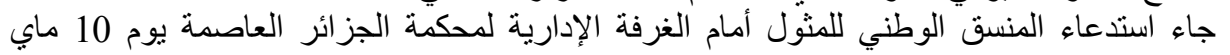

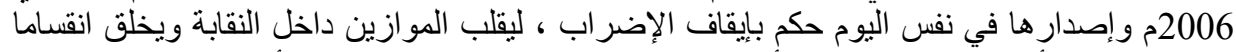

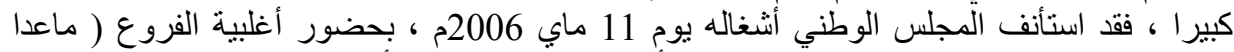

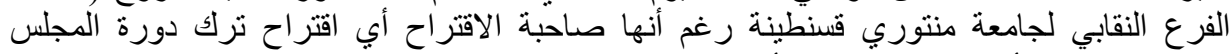

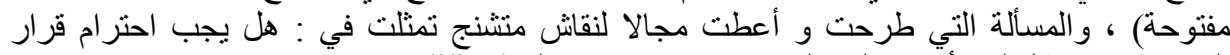

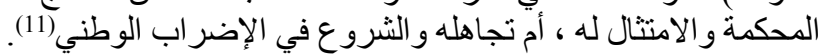




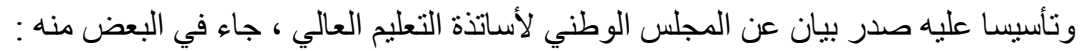

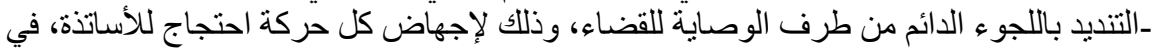

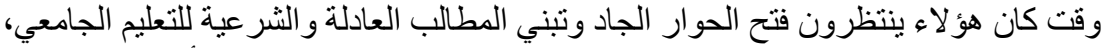
ـ احتر ام وتتفيذ قرار القضاء المتعلق بتوقيف الإضر اب الوطني لمدة أسبوع و المقر يوم 13 ماي

- تنظيم يومين للاحتجاج يوم 13 و14 ماي 2006 م للاففاع عن الحريات النقابية و حق

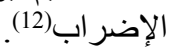

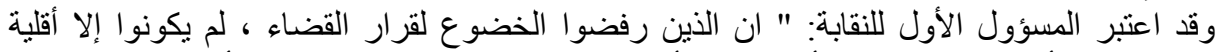

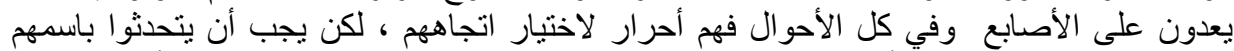

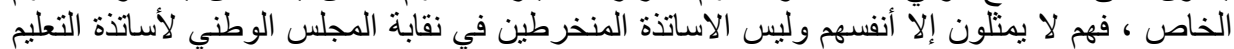

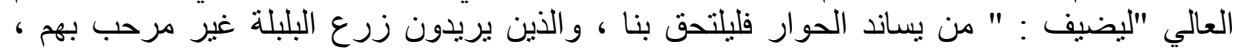

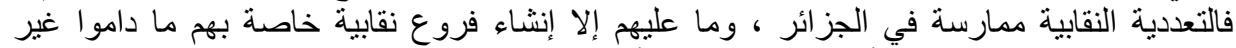

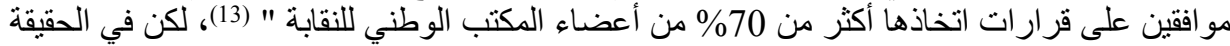

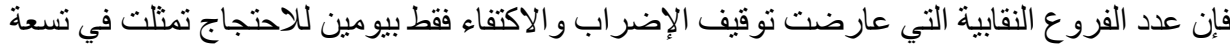
عشر (19) فرعا نقابيا(14). حيث انطوت هذه الفروع النقابية تحت مايسمى التتسيقية الوطنية للفروع النقابية للمجلس الوطني

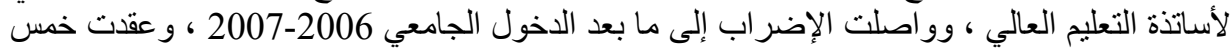

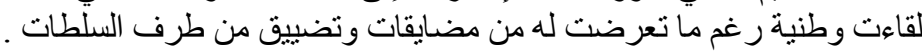

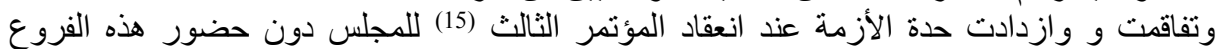

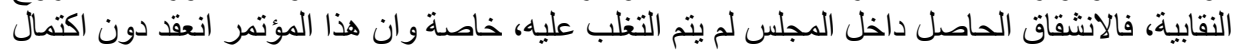

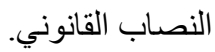

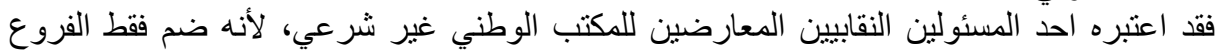

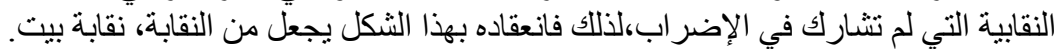

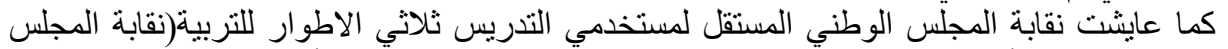

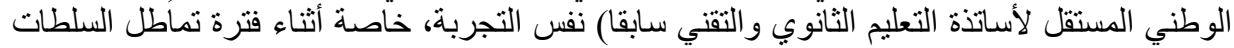

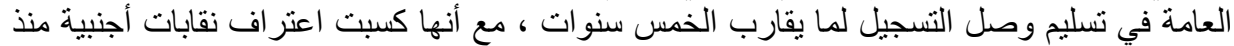

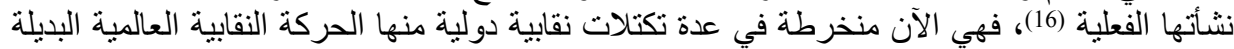
و و'aver Mondialisation

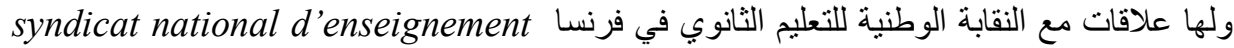
secondaire

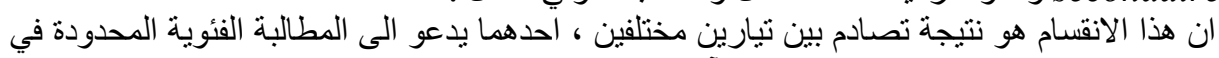

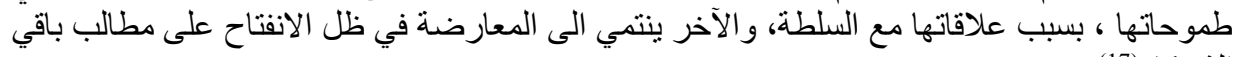

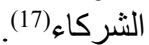

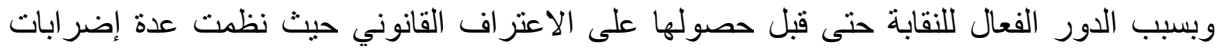

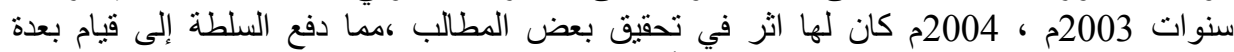

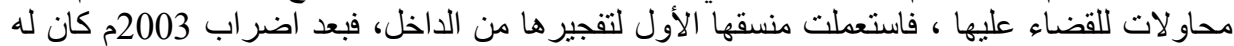

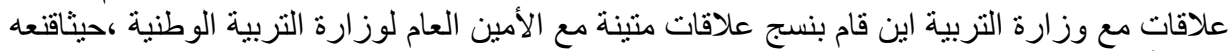

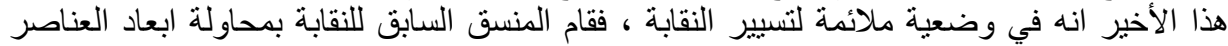

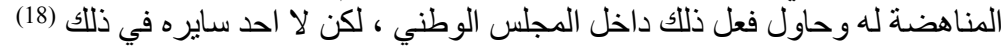

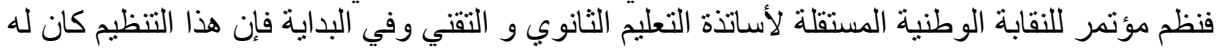

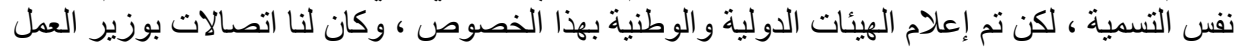
و رئيس الر ابطة الجز ائرية للدفاع عن حقوق الانسان ، وقد دفعت ممارسة الضغط المنسق النسان السابق لتغيير 


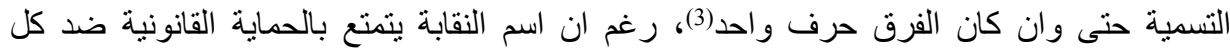

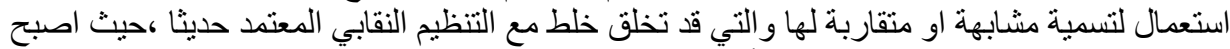

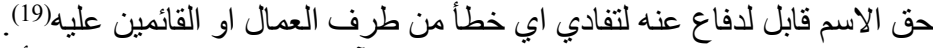

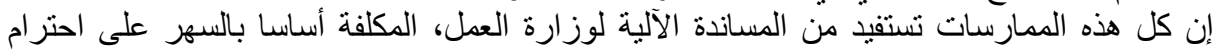

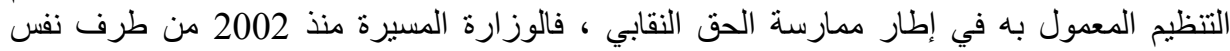

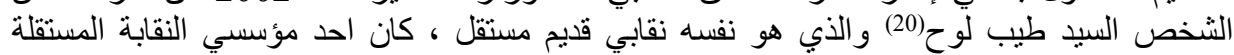

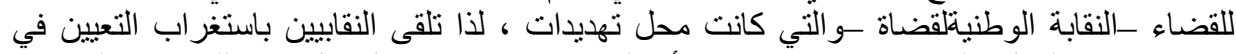
منصب وزير العمل ، لكن لاحظو ا بلا اندهاش أن الوزير منذ تعينه استسلم بكل ثبات للممارسة التي كان في لتئ ضحيتها (21) فالسلطات العمومية تريد بث الإعلان التالي: النقابات المستقلة في صفنا، كما هي العادة فالسلطات تريد

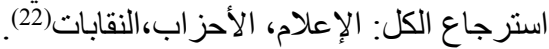

لذلك فان الهيئات الدولية المختصة تنبه اللى ضرورة الإنى الاخذ في الاعتبار خصوصيات الساحة النقابية

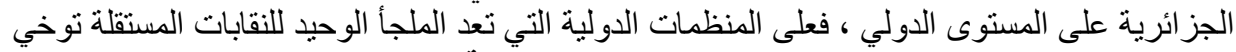

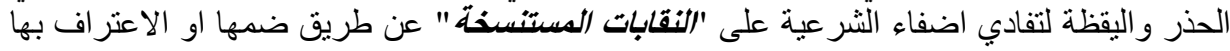

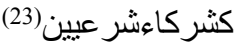

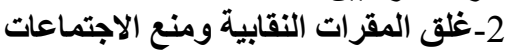

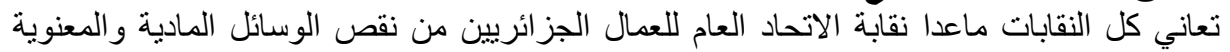

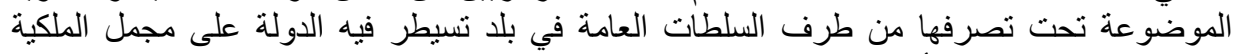

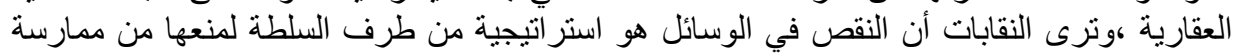

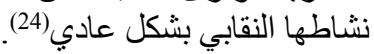

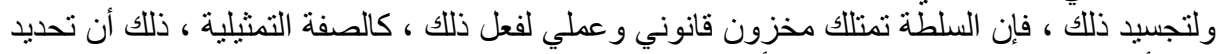

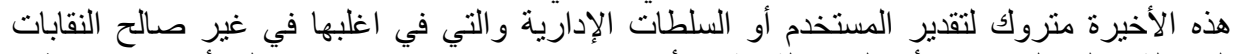

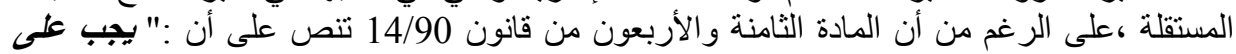

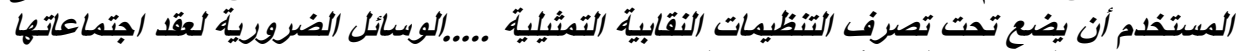

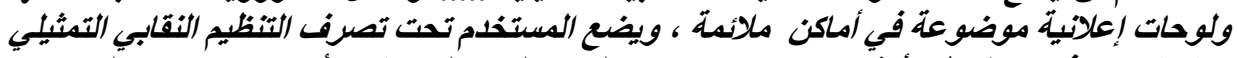

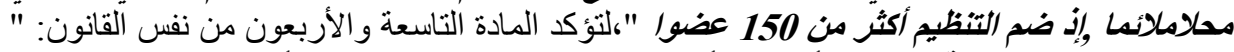

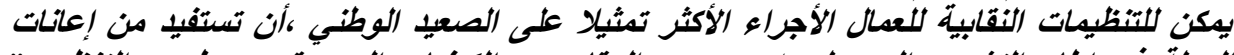

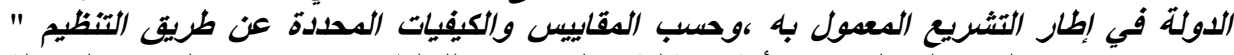
فالإشارة في هذا النص إلى النقابات الأكثر تمثيلية ، التي تسمح للسلطات من حرمان النقابات المستقلة

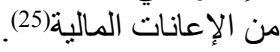

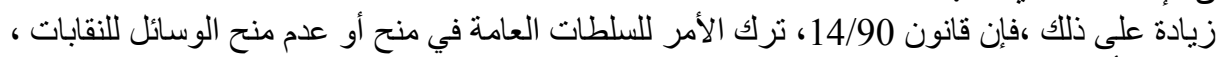

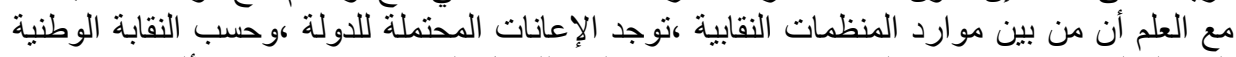

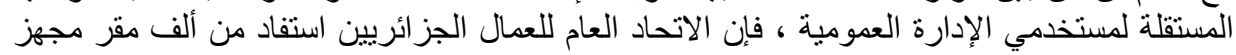

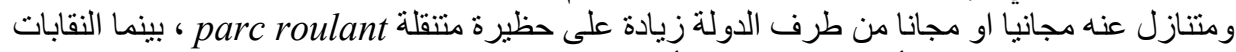

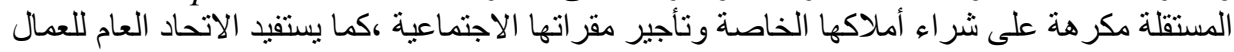

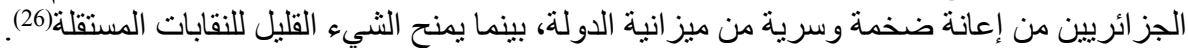

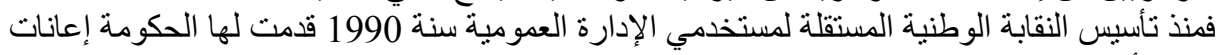

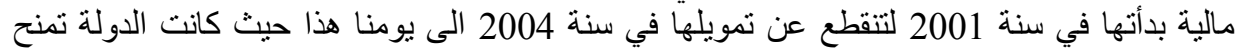

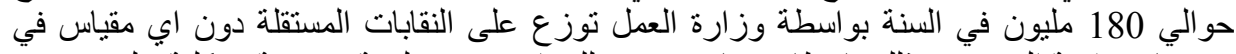

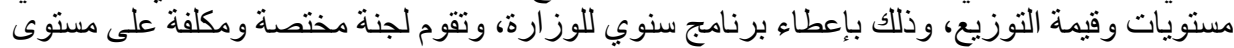

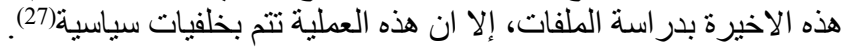




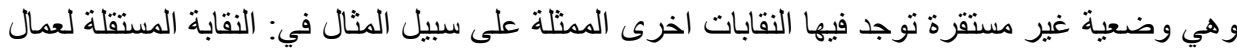

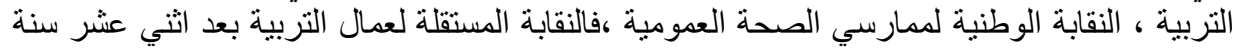

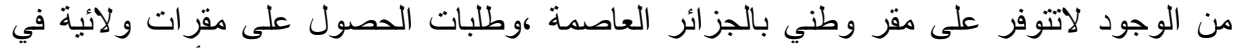

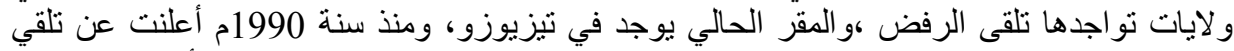

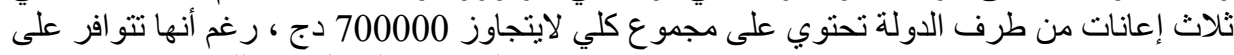
ثلاثة و عشرون انتداب ومنو اجدة في ثمانية وعشرون ولانية ولاية ، لكنها في المقابل لا تملك إلا خمسة مكاتب

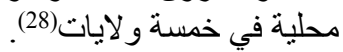

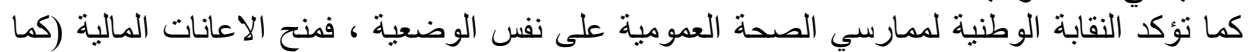

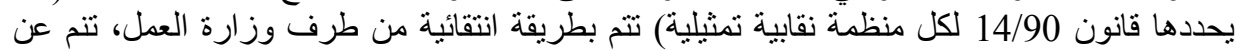

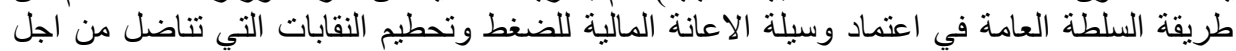

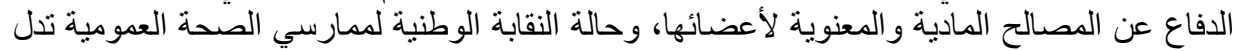

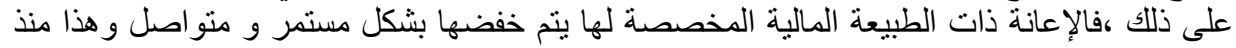

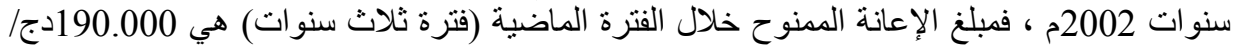

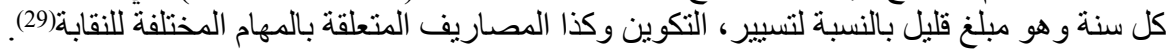

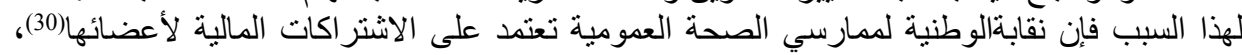

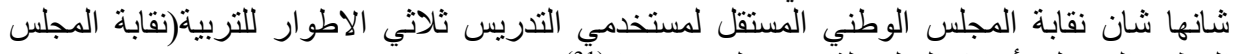

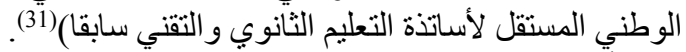

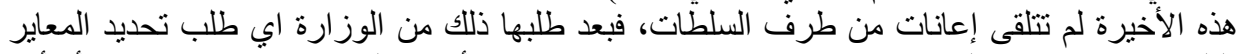

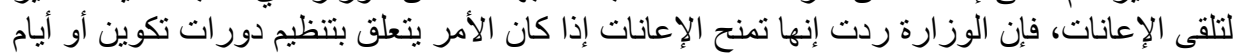

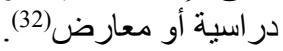
وبعد سنة2004 حولت الوزارة التمويل الى النقابات المستنسخة حتي اذا تم محاسبتها من طرف

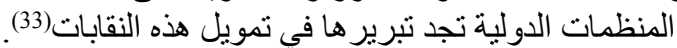

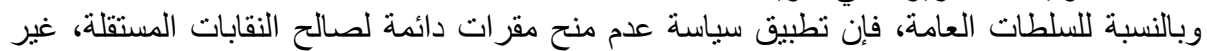

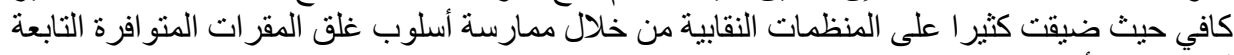
لها أستنادا لأسباب غير جدية و غير مؤسية.

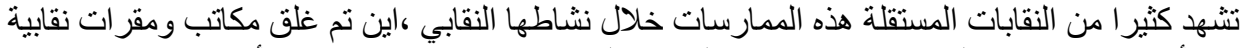

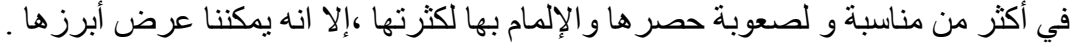

تعرضت النقابة الوطنية المستقلة لمستخدمي الإدارة العمومية لغلق المقر الوطني للاتحاد الوطني

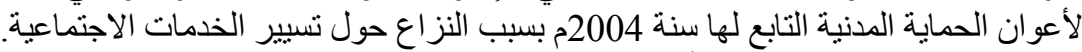

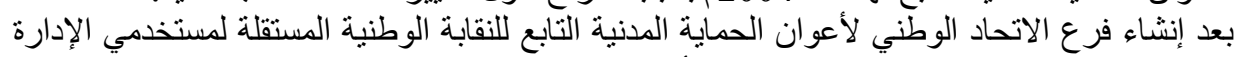

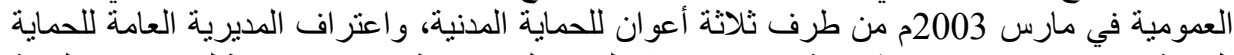

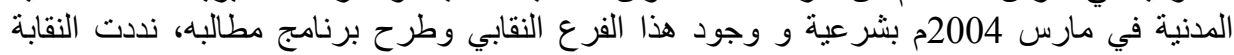

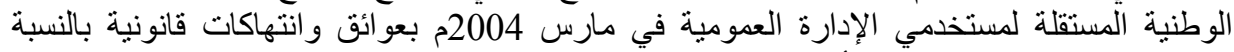

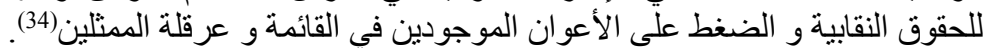

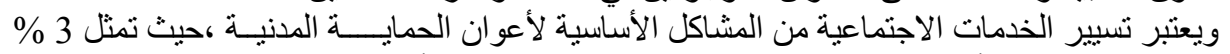

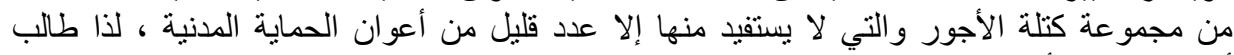

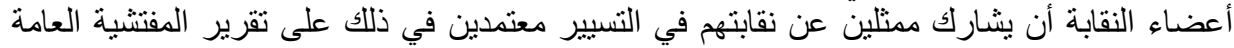

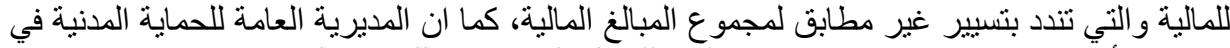

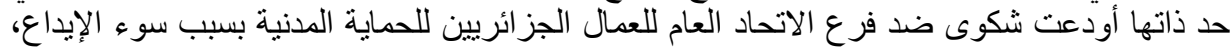

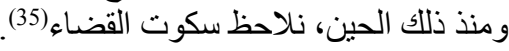




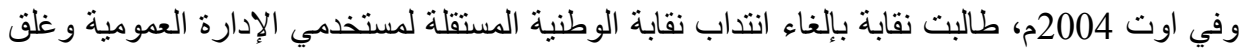

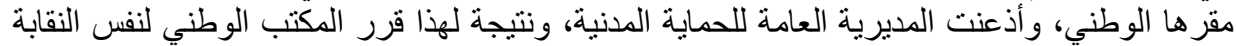

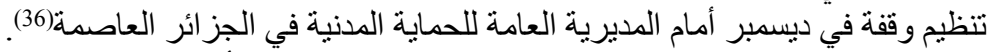

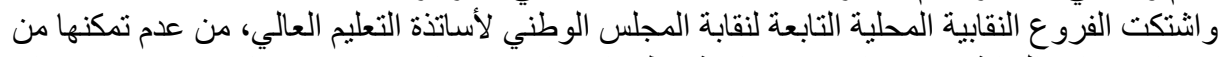

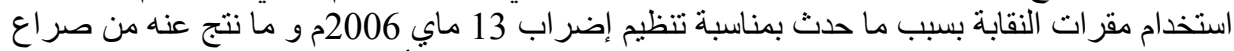

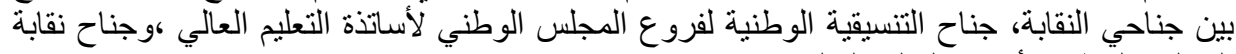
المجلس الوطني لأساتذة التعليم العالي . لألئ.

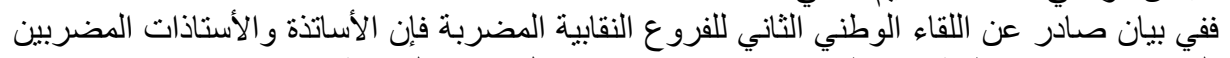

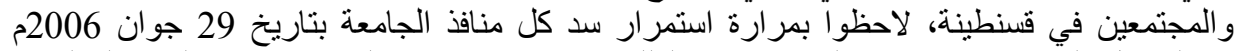

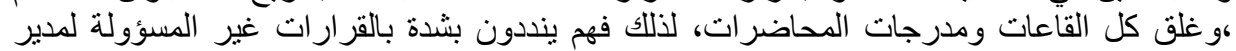
جامعة الاخوة منتوري قسنطينة (37).

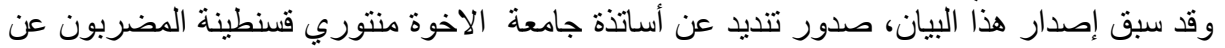

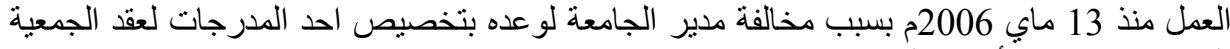

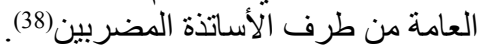

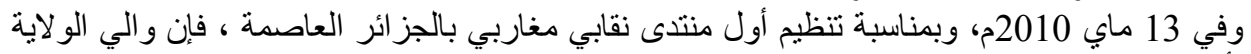

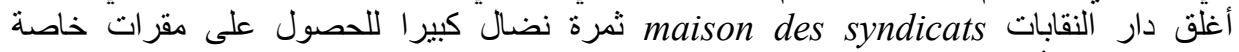

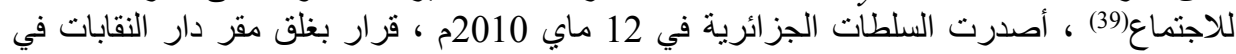

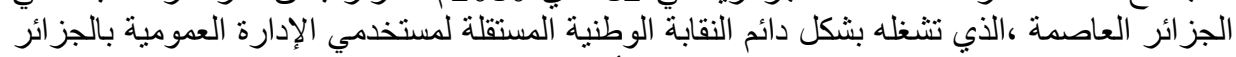

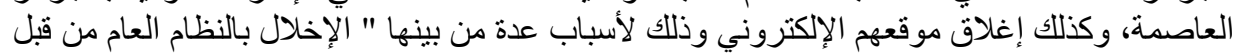
شاغلي المقر "(40).

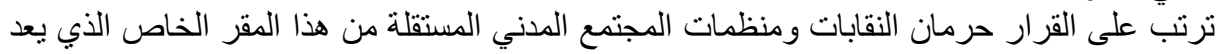

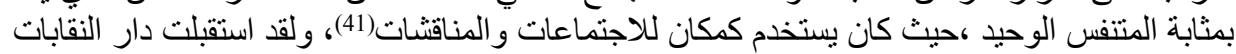

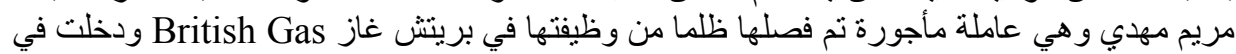

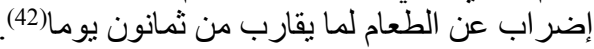

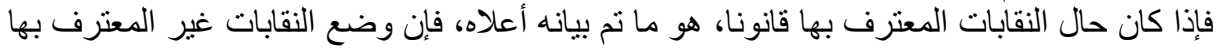

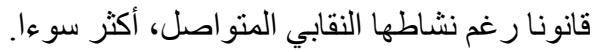

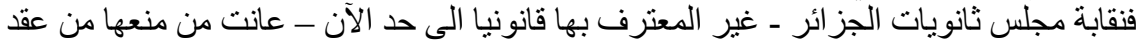

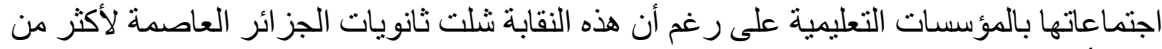

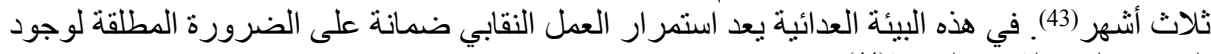
النقابات المستقلة في الساحة (44) فئنة

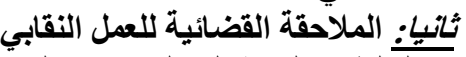

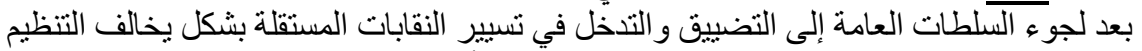

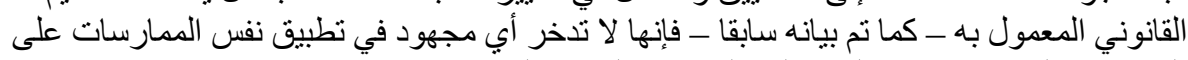

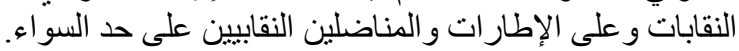

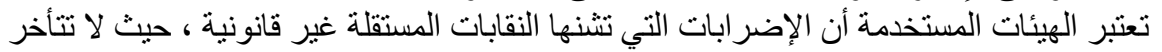

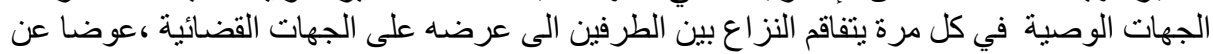

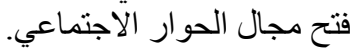

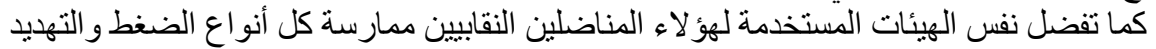

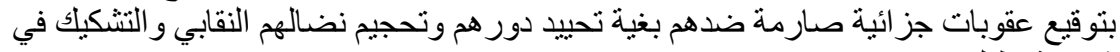
1- 1 - nل ضد النقابات 
إن الملاحقة القضائية هي تهايد كبير لكيفية ممارسة الحرية النقابية،و لحق النقابات في ممارسة حق الاضر اب المكرس دستوريا.

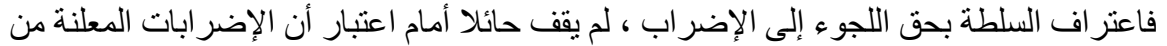

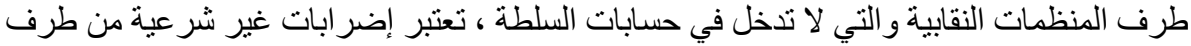

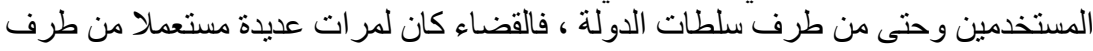

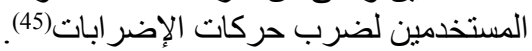

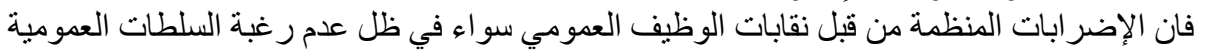

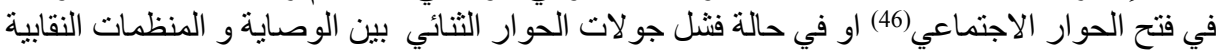

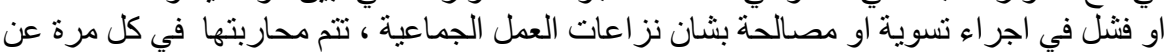

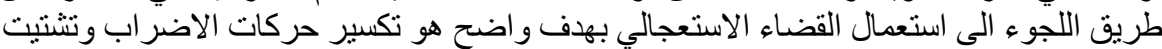

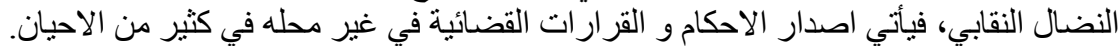

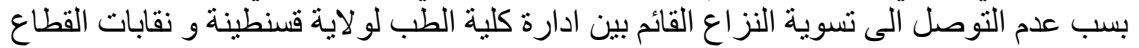

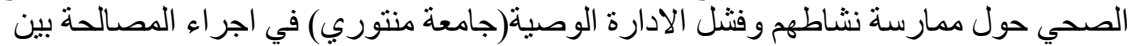

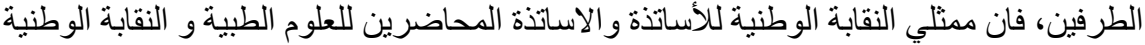

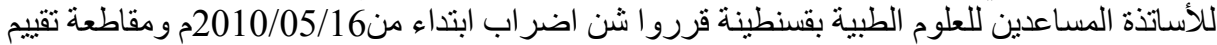

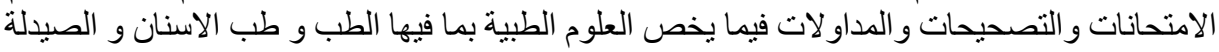

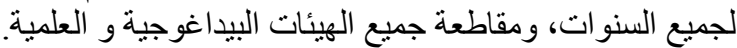

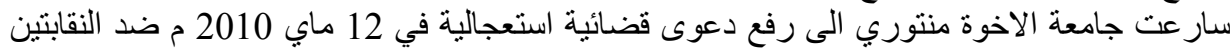

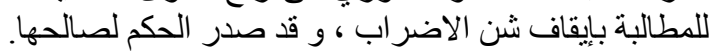

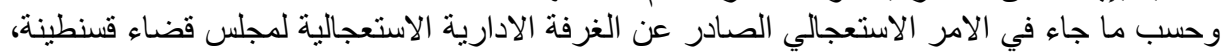

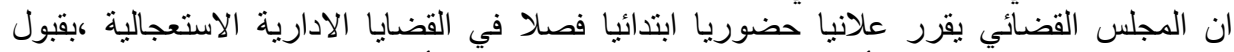

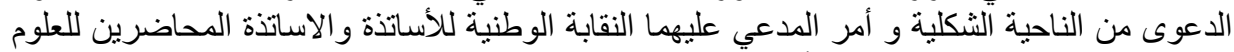

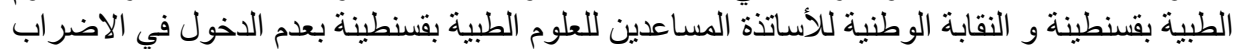

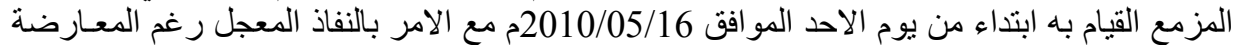

$$
\text { وقد اسس الامر الاستعجالي قراره على وجهين جوهريين هما: }
$$

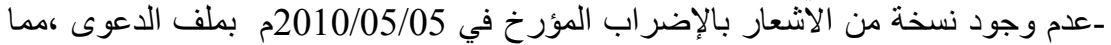

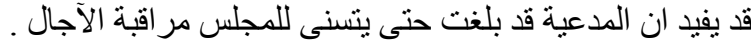

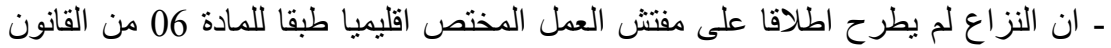

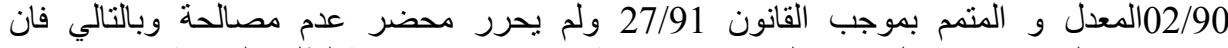

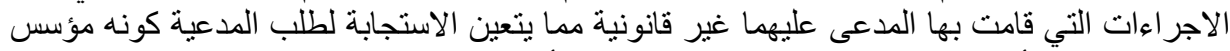

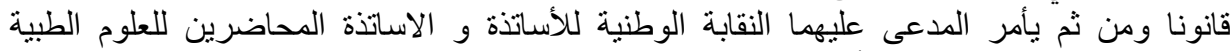

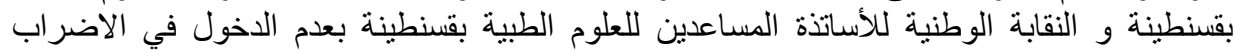

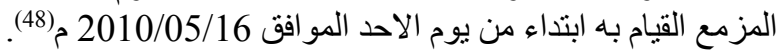

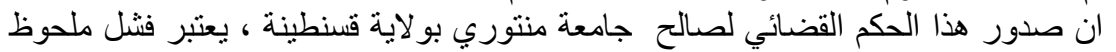

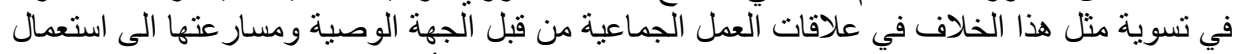

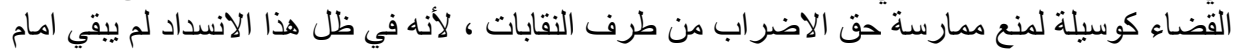

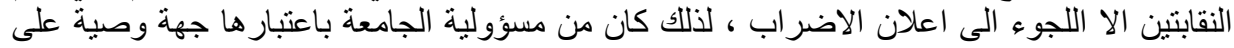

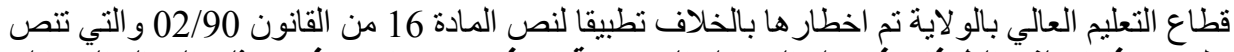

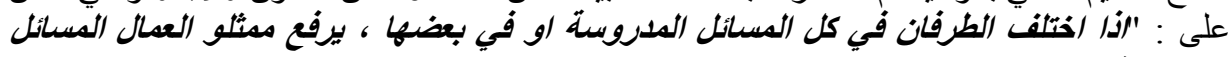


ـالسلطات الادارية المختصة في مستوى البلدية او الولاية التسي تتنـي اليها المؤسسة او

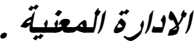

ـالوزارة مثثليهم المخولين اذا كاتت المؤسسات او الادارات المغنية تلذل في نطاق

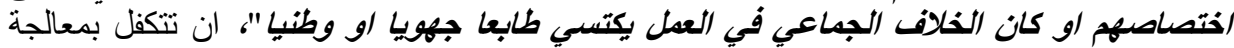

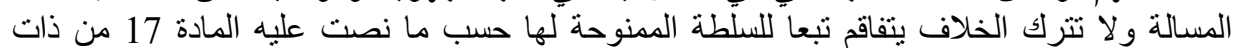

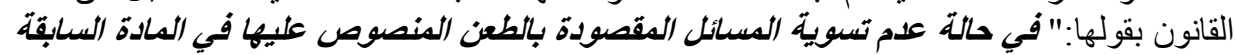

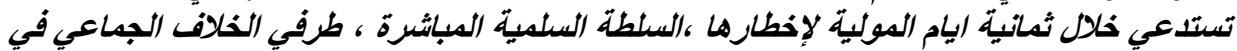

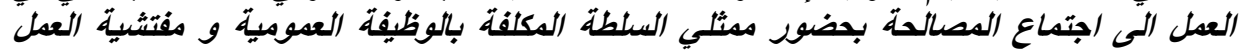

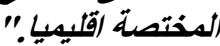

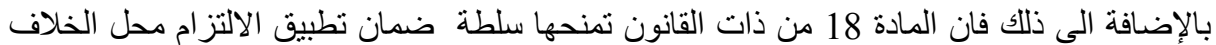

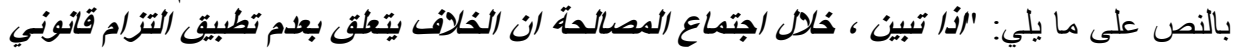

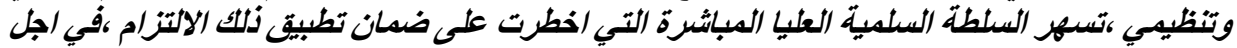
لا يتعدى ثلاثين يوما من تاريخ الاخطار ". خاصة وان جدول اعمال الجمعية العامة الاستثنائية التي عقدتها النقابت النقابتين في 2010/05/04 تضمن

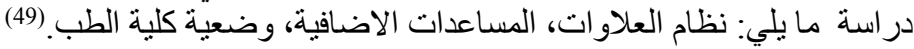

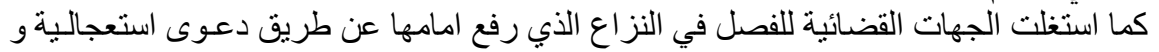

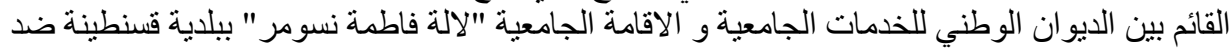

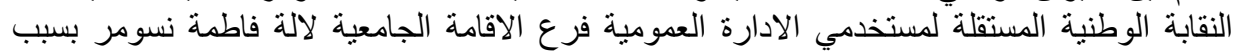

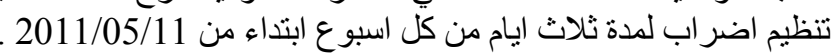

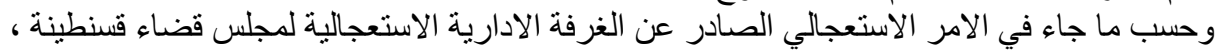

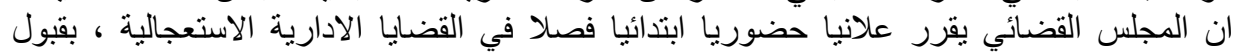

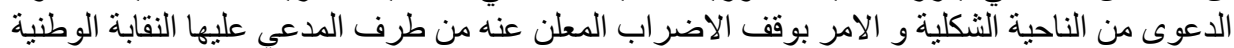

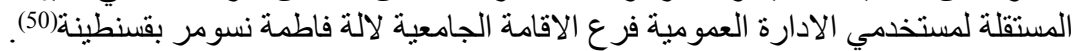

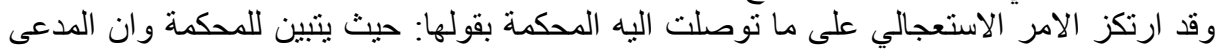

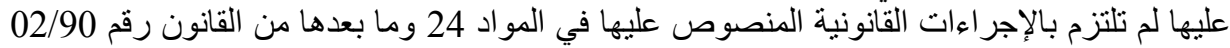

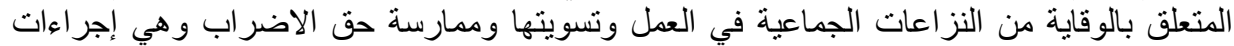

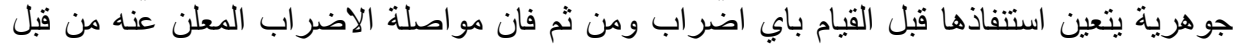

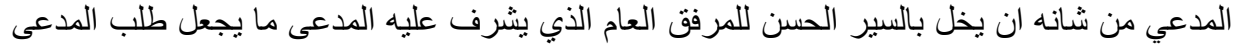

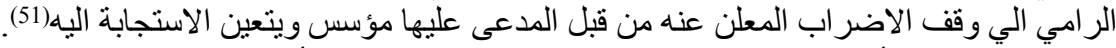

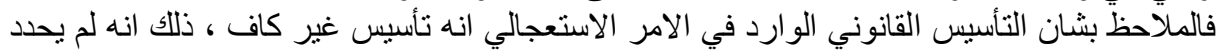

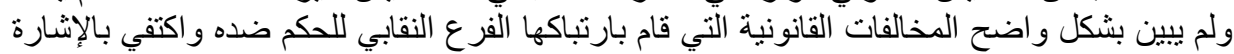

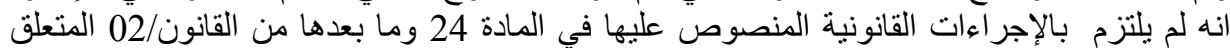

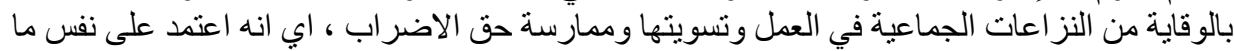

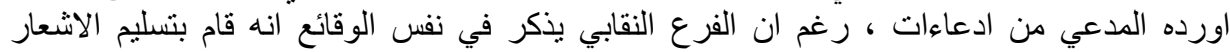

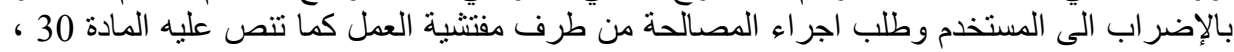

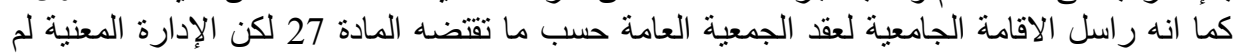

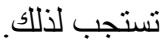
وفي حالات اخرى تحتكم الجهات القضائية في اصدار احكامها لتوقيف إضر ابات النقابات استنادا الى لى التئي

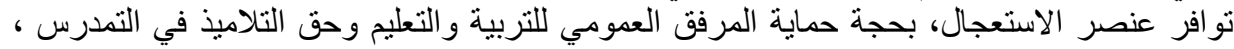

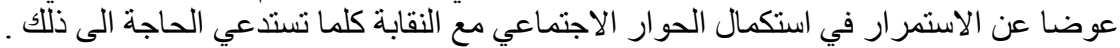

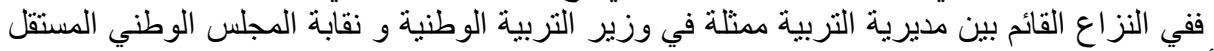
لأساتذة التعليم الثانوي والتقني ممثلة في المنسق الوطني بسبب النظام التعويضي و ملف التفائ الخدمات 


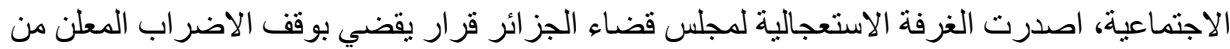

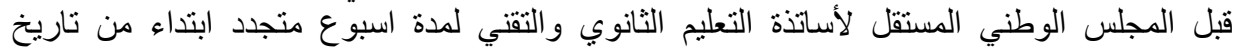

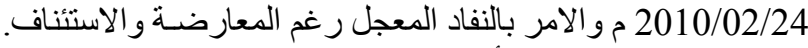

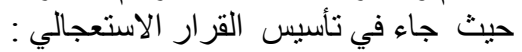

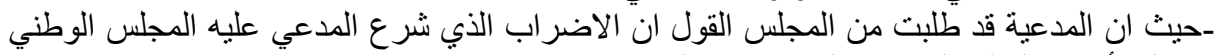

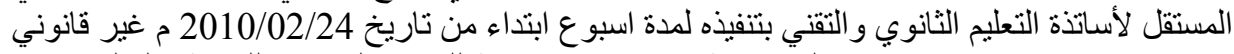

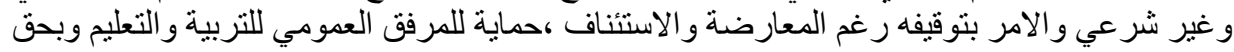

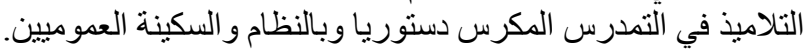

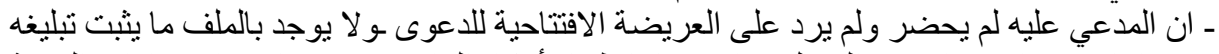

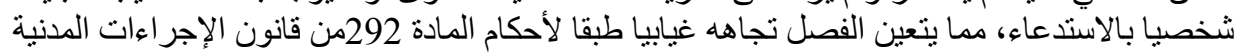

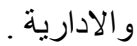

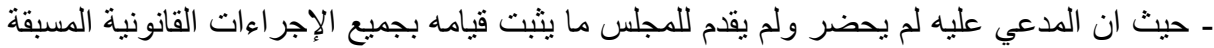

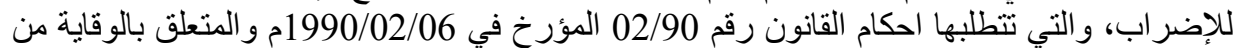

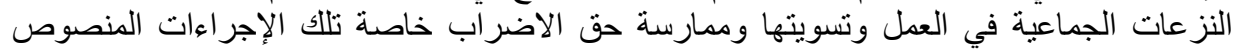

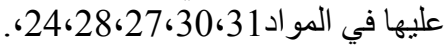

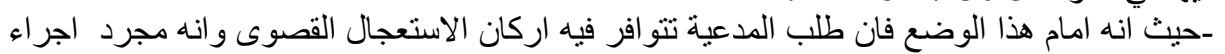

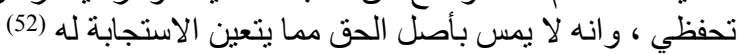

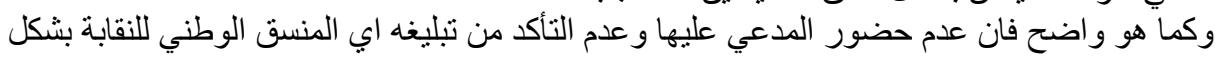

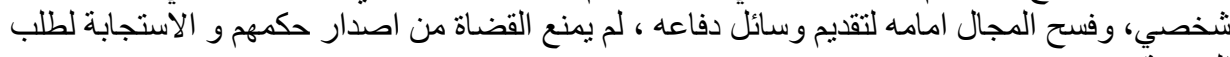

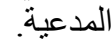
ونعليقا على ذلك، فقد صرح المنسق الوطني للنقابة ،" لم نبلغ بالقرار، و واقول للوصاية ان العدالة

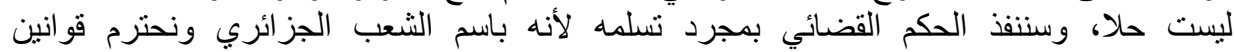

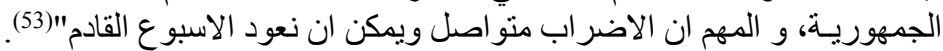

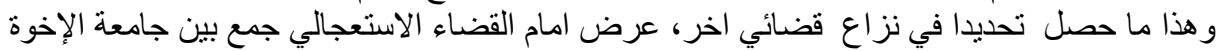

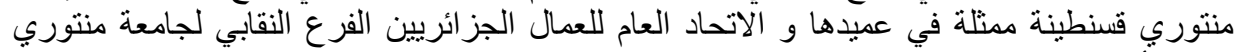

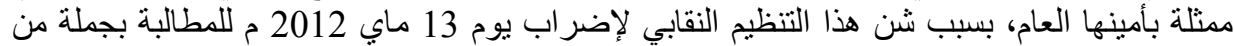

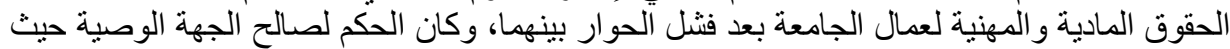

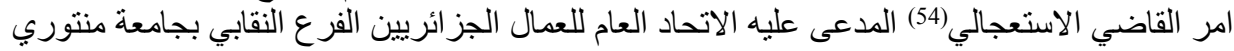

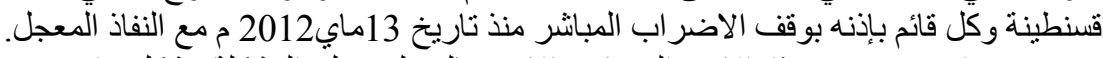

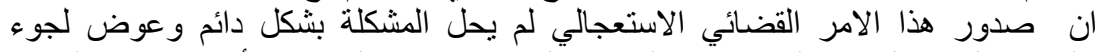

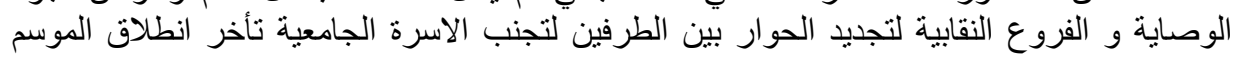

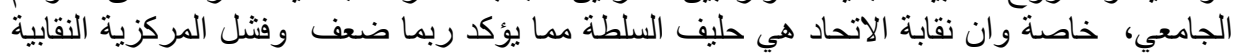

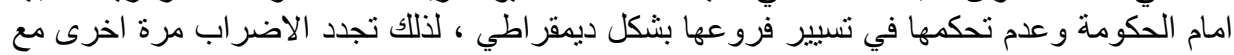

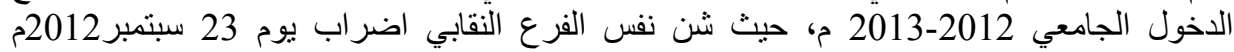

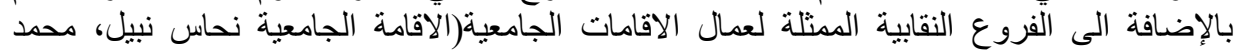

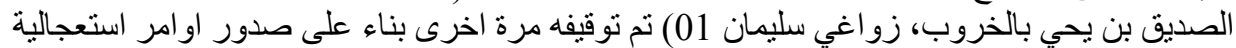

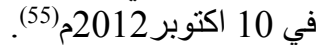

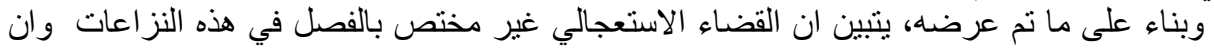

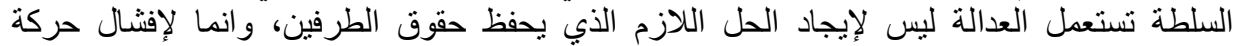

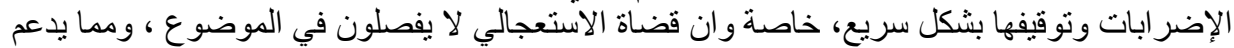

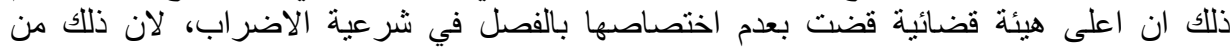
اختصاص القضاء العادي وليس القضاء الاستعجالي. 


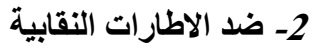

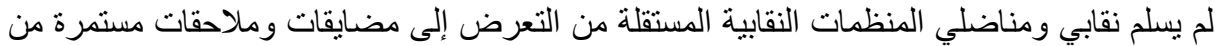

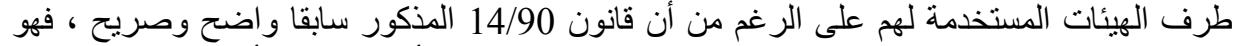

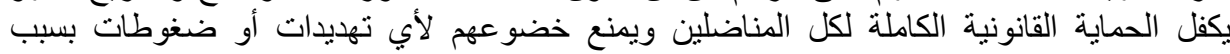

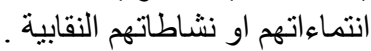

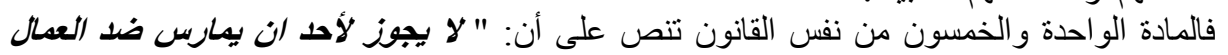

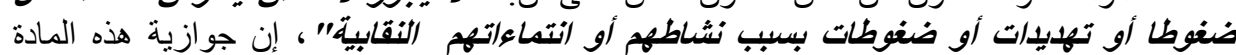

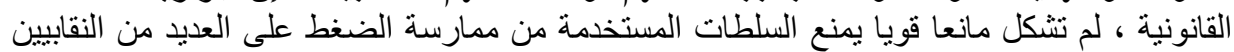

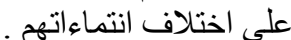

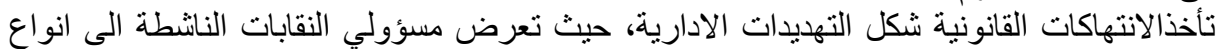

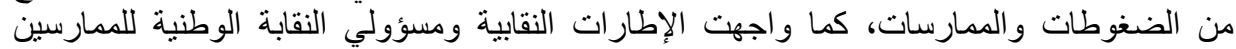

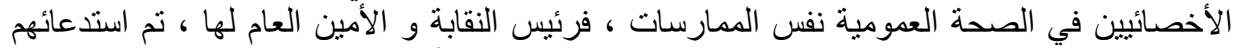

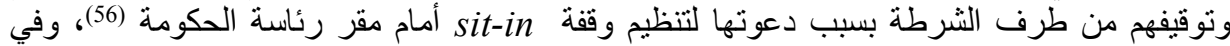

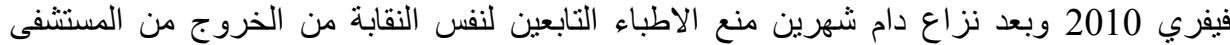

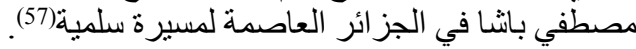
وفي 20 سبتمبر 2011 تم اعتقال السيدة فليل مليكة رئيسة اللجنة الوطنية لعمال ما قبل التيل التثغيل

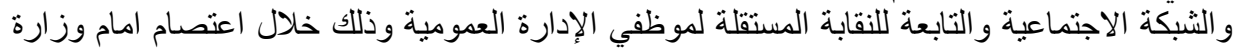

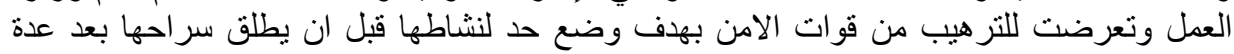

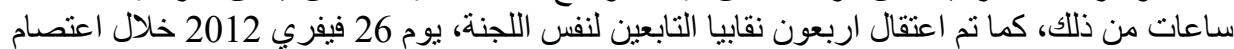

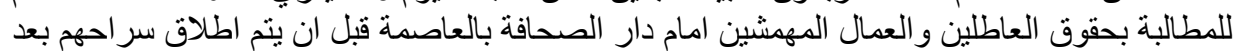

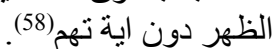
كما تعرض أساتذة التعليم العالي المنضوين تحت لواء التهبي التسيقية الوطنية لفروع المجلس الوطني لأساتذة

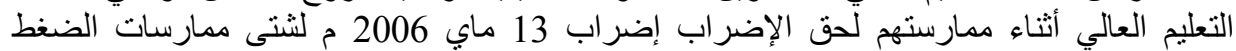

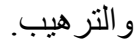

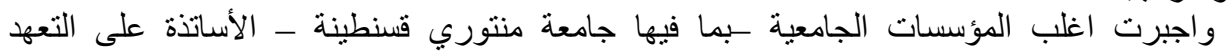

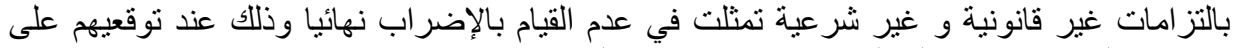

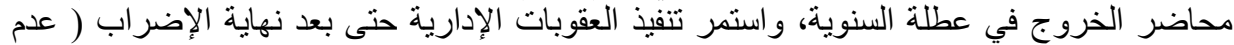

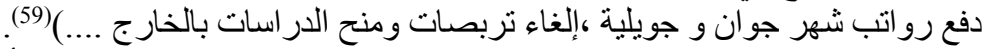

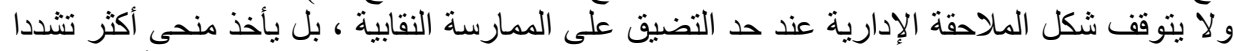

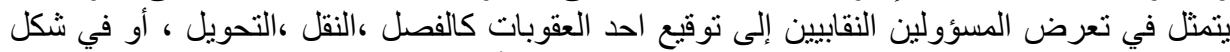

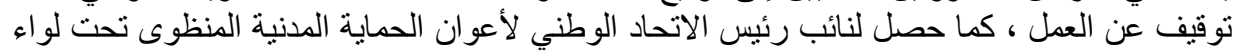

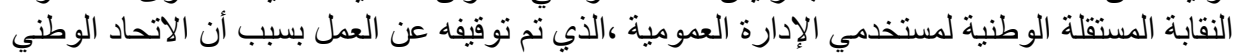

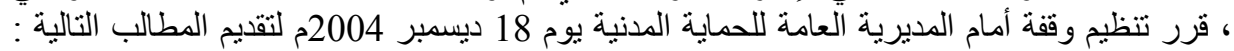

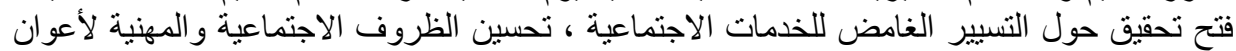

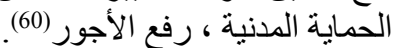
وقد تلقى إلى جانب ذلك نائب رئيس الاتحاد الوطني عقوبة أخرى بعد توقيفه عن العمل لمدة ستة

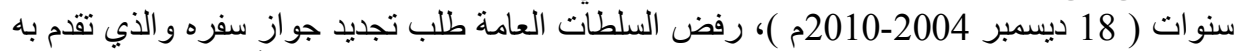

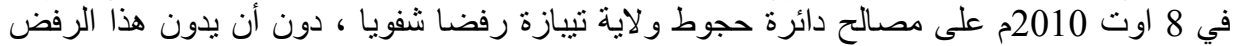

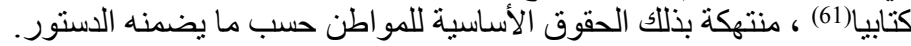

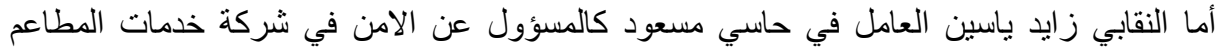

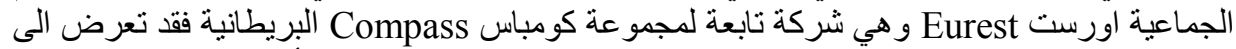
الفصل من عمله، بسبب انثاء فرع نقابي (1400 عامل في الجمعية العامة التأسيسية) فحرمته الثركة فيطة 
من هذا الحق واصبح بين عشية وضحاها ذلك الموظف النموذجي المكافئ مر ارا بمكافأت مالية غير

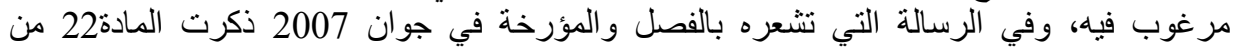

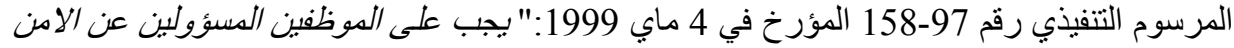

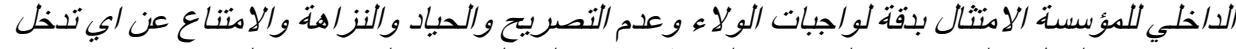

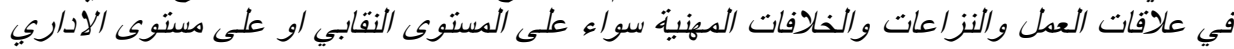

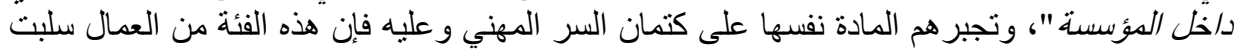
منها حريتها النقابية("62). و هو نفس ما حدث للنقابيين التابعيين للنقابة الوطنية المستقلة لمستخدمي الإدارة العمومية و الذين طالبوا

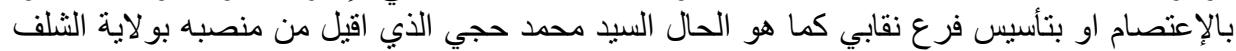

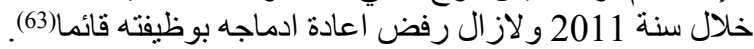

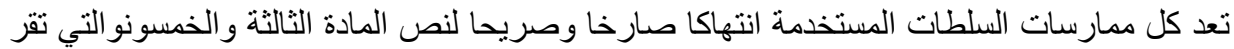

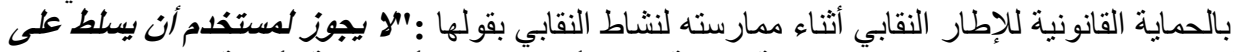

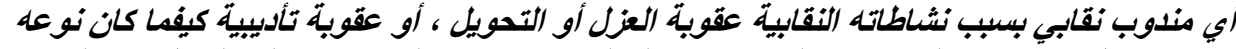

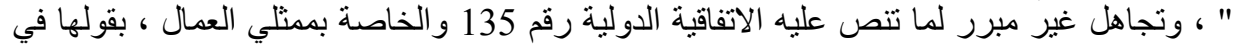

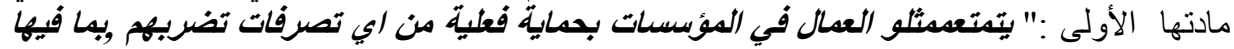

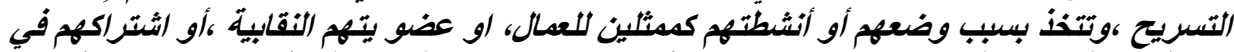

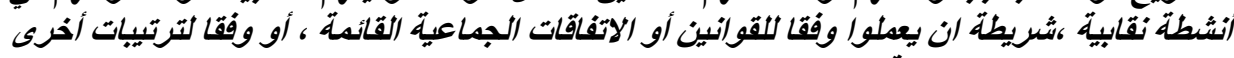

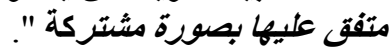

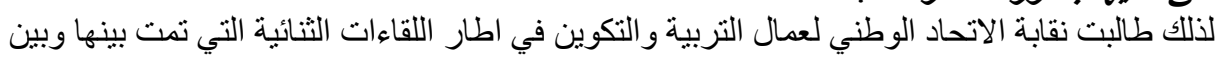

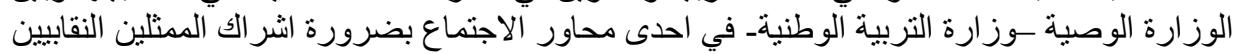

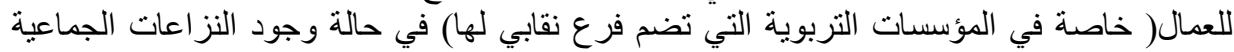

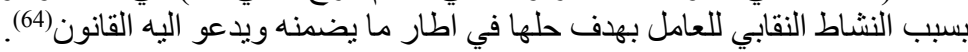

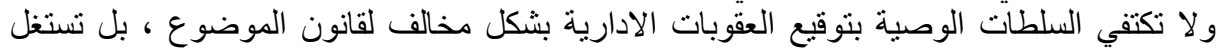

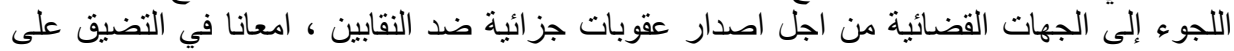

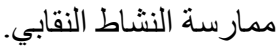

بسبب فثل إجراءات الصلح مع الإدارة ، قامت هذه الاخيرة بغلق مكتب نقابي تابع للنقابة الوطنية

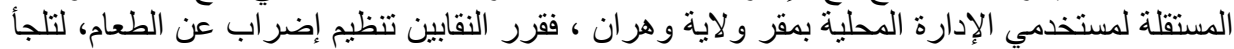

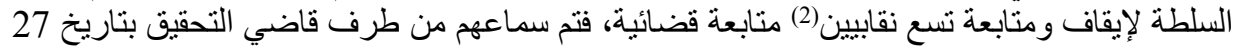

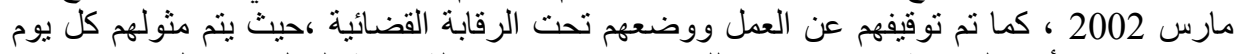

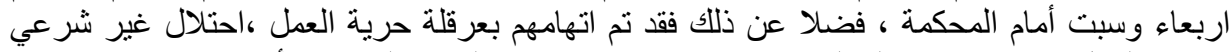

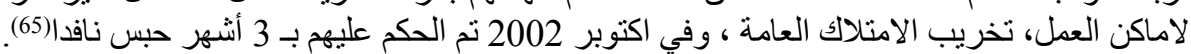

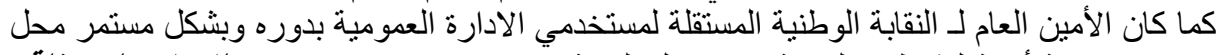

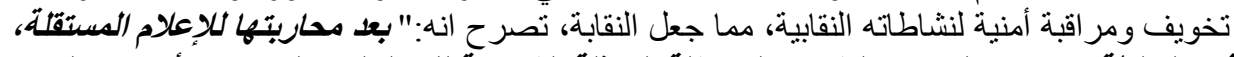

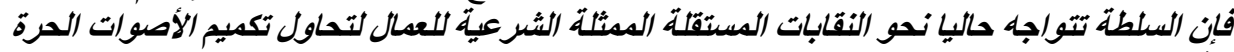

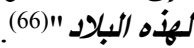

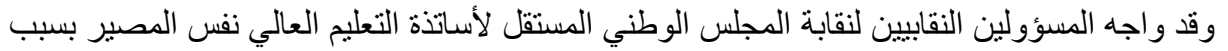

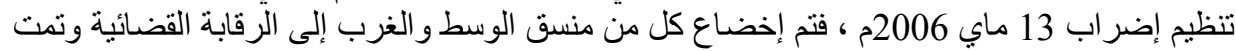

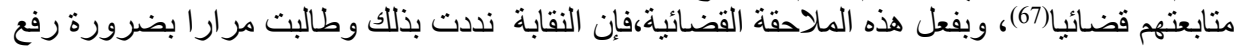

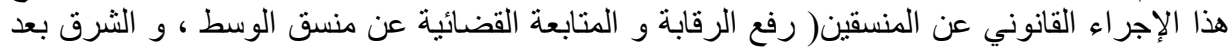

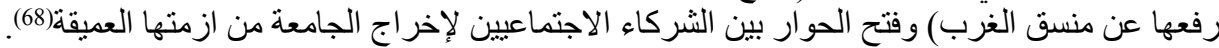

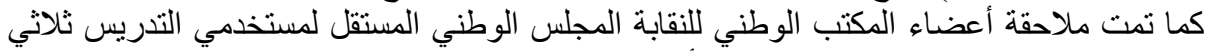
الاطوار للتربية (المجلس الوطني المستقل لأساتذة التعليم الثانوي والتقني سابقا )خلال المرحلة التي 
سبقت الاعتر اف القانوني بها ، حيث مثل ستة أعضاء من المكتب الوطني للنقابة، أمام القضاء بتهمة الإنهاء

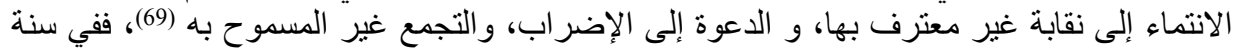

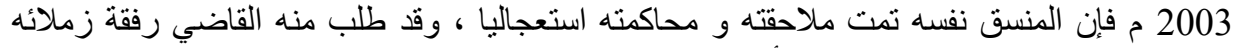

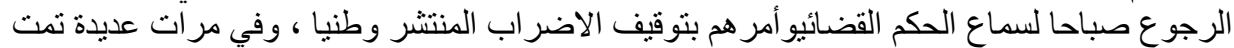

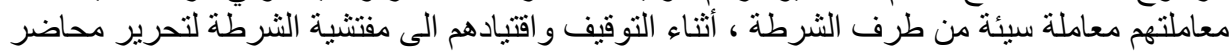

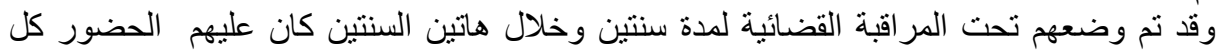
خمسة عشر يوما امام القاضي قاض التحقيق بالو لإية ، فقط المنسق السابق و الذي خان خان مبادئ النقابة

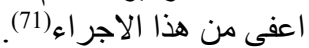

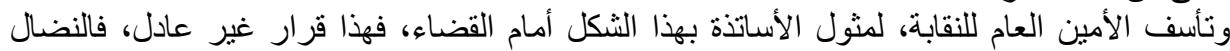

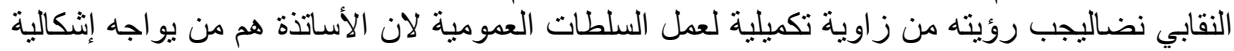

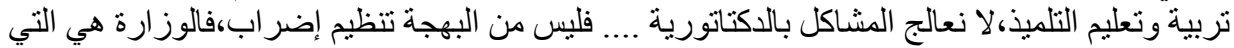

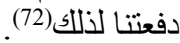

وحتى بعد الاعتراف القانوني بالنقابة ،فإن الملاحقة القضائية لم تتوقف بل استمرت بشكل يؤكد على لقابع

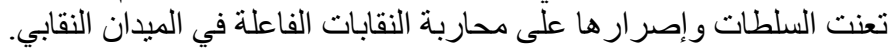

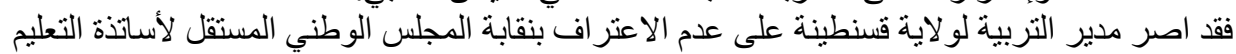

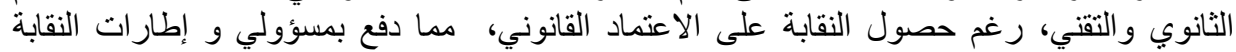

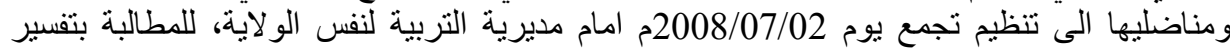

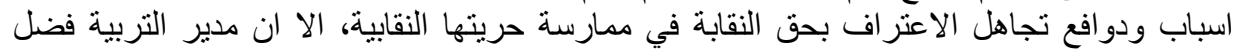
استدعاء الامن الوطني لتفريق التجمع (73).

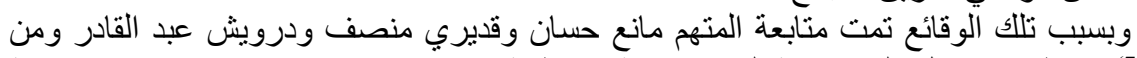

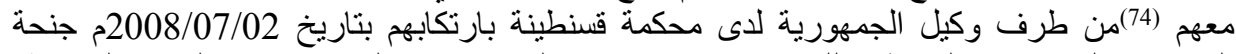

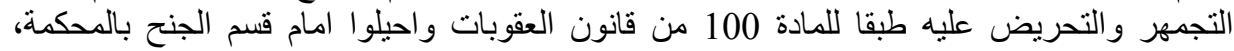

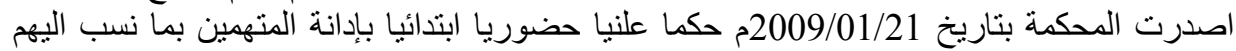

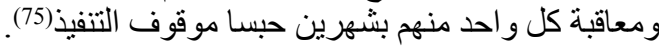
ومما يؤكد على ان مدير التربية لو لاية قسنطينة اراد فقط عرقلة التهابنة النقابة ومنعها من ممارسة نشاطها

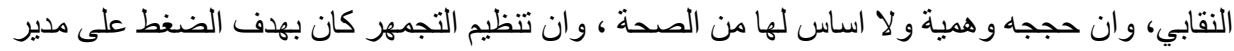

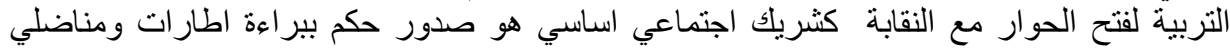

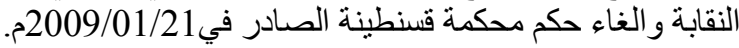

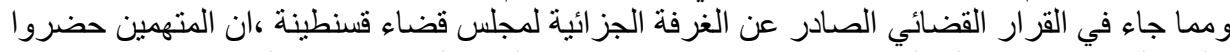

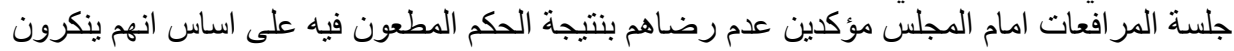

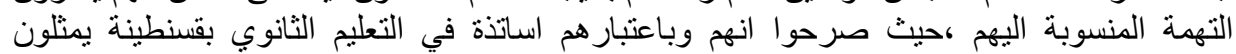

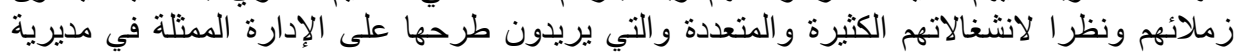

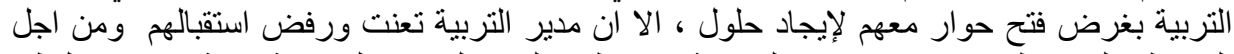
الضغط عليهم نظموا تجمهر المقر المديرية في اطار الحق النقابي ولم يحدثوا اية مساس التُ بالنظام العام (76).

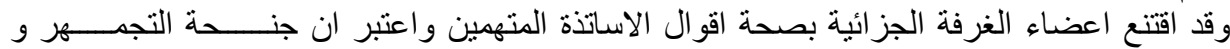

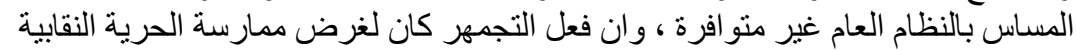

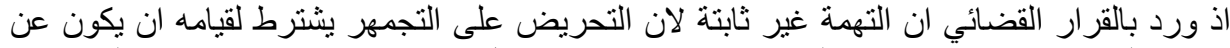

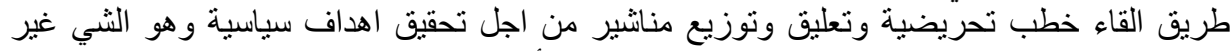

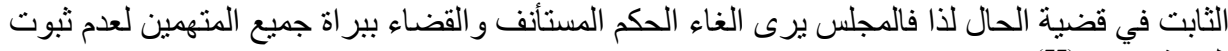


فإذا كان القضاء عادلا مع قضية هؤل لاء النقابيين ، فالوضع لم يكن نفسه عندما تمت ملاحقة النقابي زياد

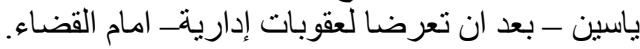

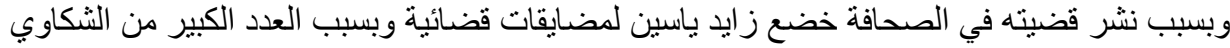

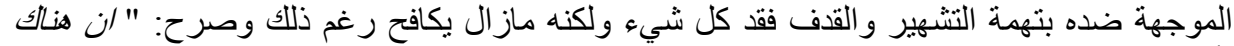

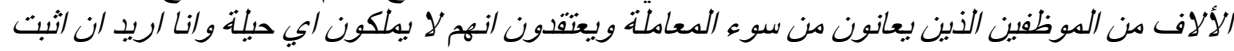

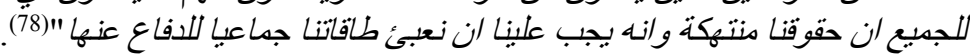

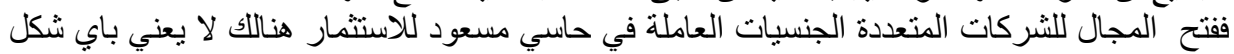

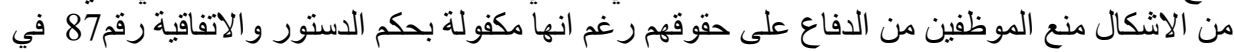

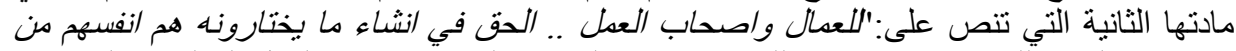

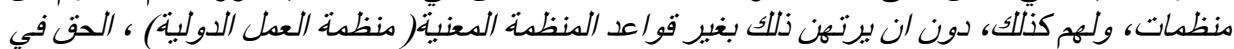

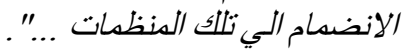

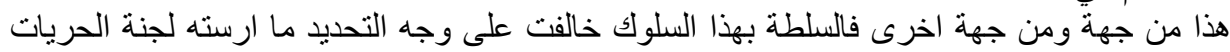

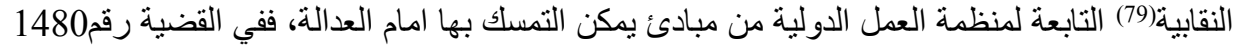

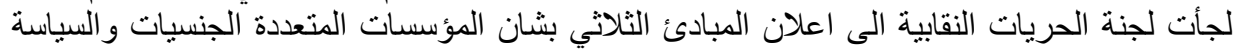

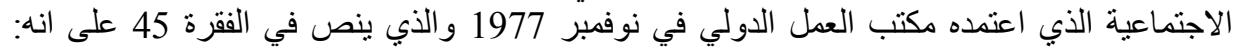

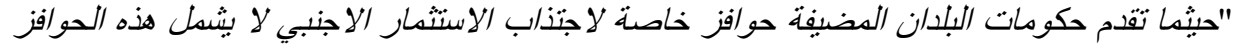

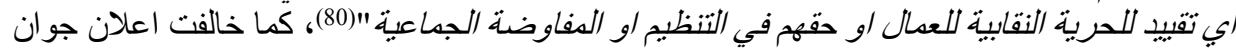

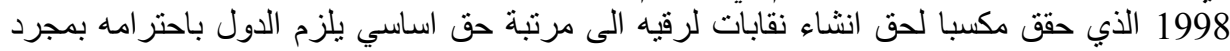
انتمائها الى المنظمة الدولية للعمل (81).

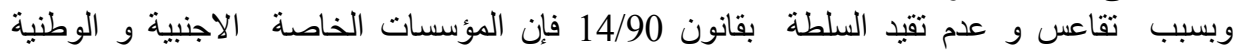

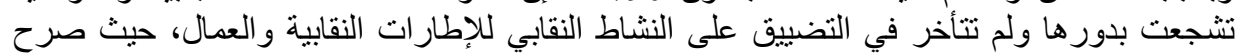

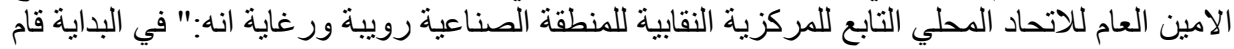

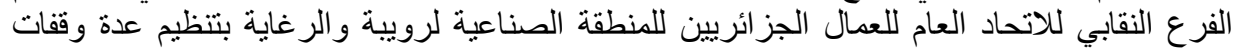

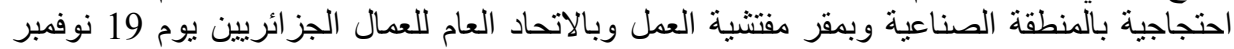

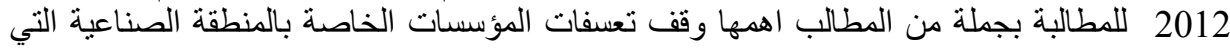

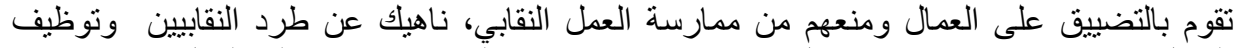

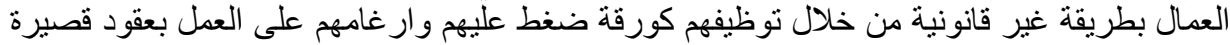

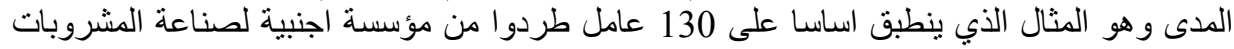

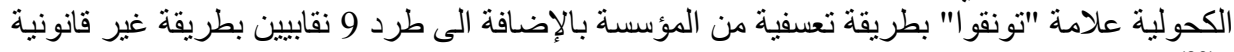

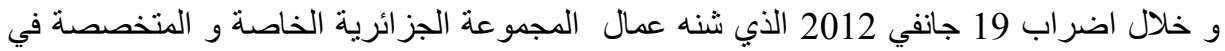

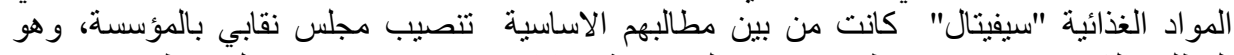

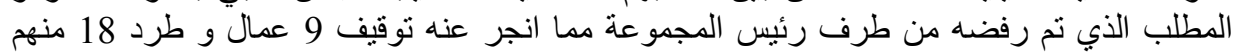

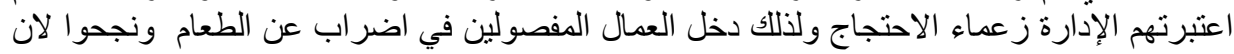

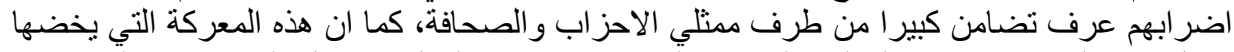

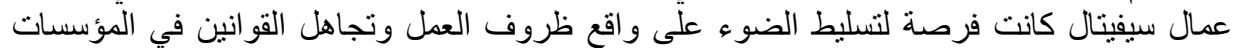

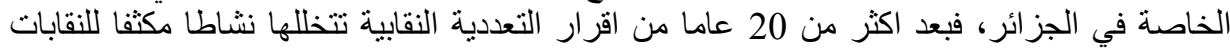
المستقلة، لايز ال القطاع الخاص مغلقا امام هذا الحق الذي يضمنه القانون لمجموع العمال. (83) 
يعتبر احترام استقلالية العمل النقابي مبدأ من المبادئ الجوهرية الكفيلة بتحقيق الاستقرار و السلم

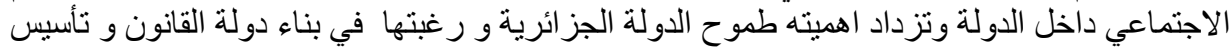

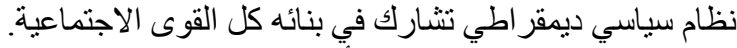

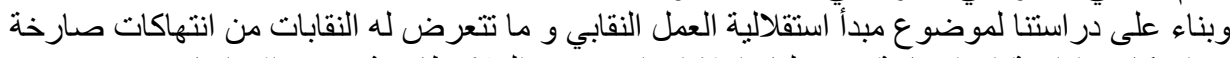

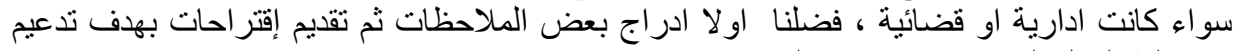

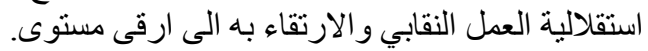

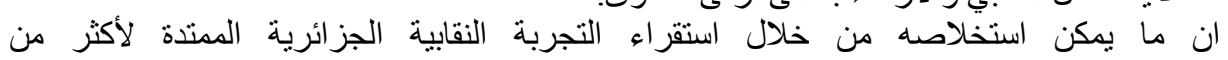

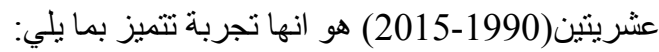

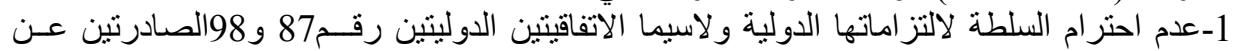

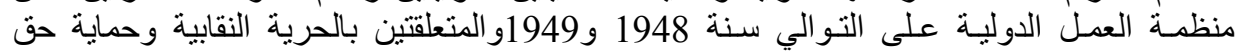

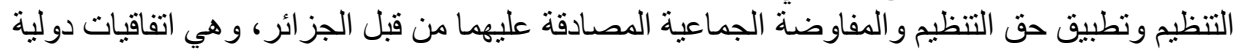

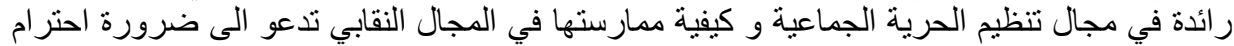

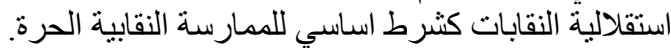

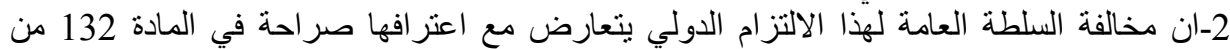

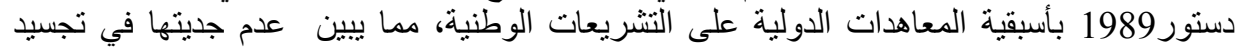

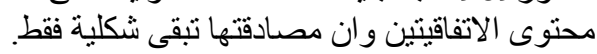

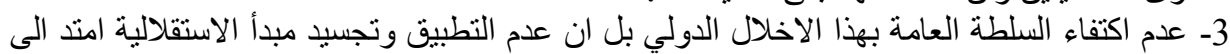

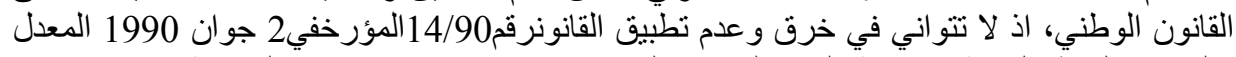

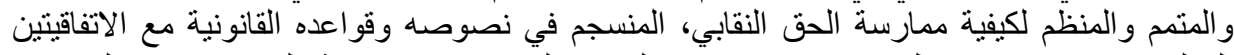
الدوليتين رقم 87 و98 المذكورتين اعلاه، و الداعي الى احترام ممارسة النقابات لاستقلاليتها في التئين

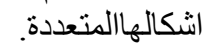

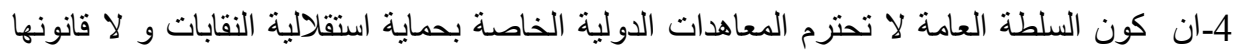

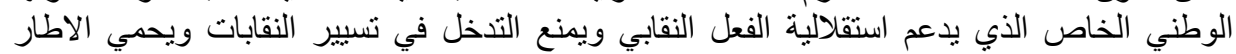

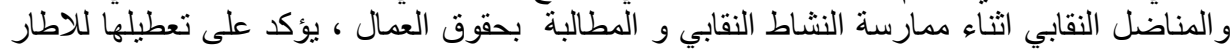

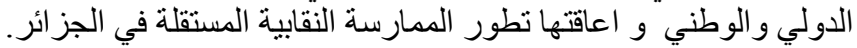

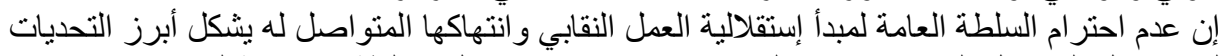

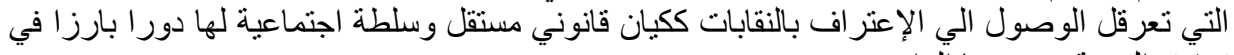
تحقيق التنمية بمفهومها الو اسع. لذللك فضلنا ادر اج مجمو عة من الاقتر احات :

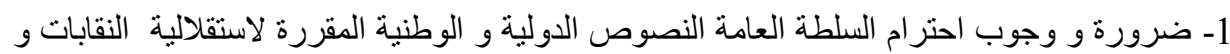

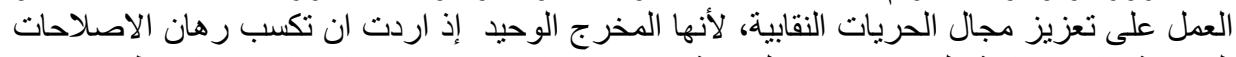

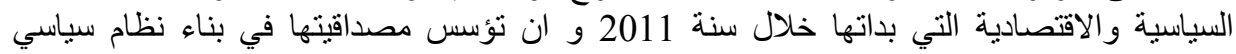

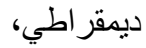

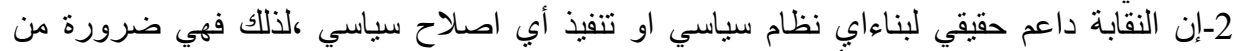

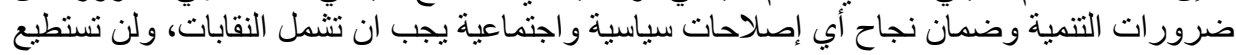

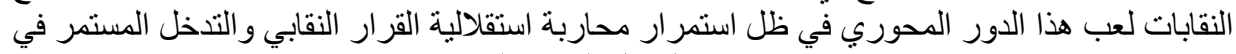

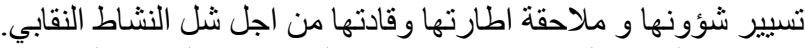

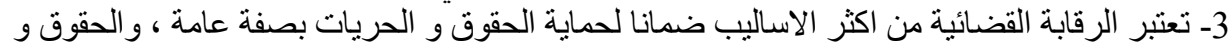

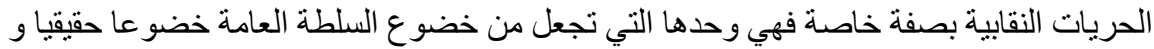
تتوقف فعالية الرقابة القضائية على ضرورة اسنادها الى هيئة قضائية مستقلة حتى يكون فعلا جهة 


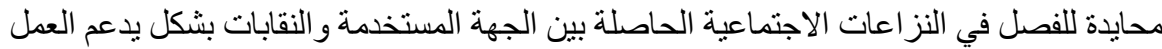

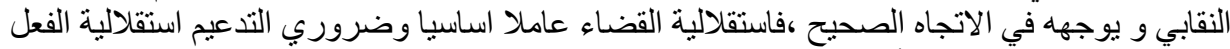

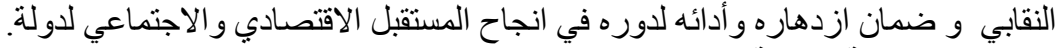

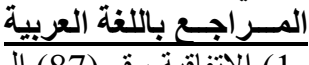

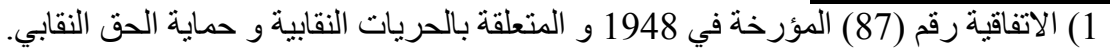

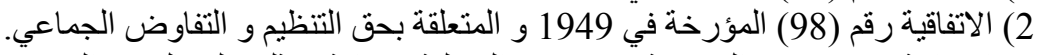

3) الاتفاقية رقم (135) المؤرخة في 1971 المتعلقة بحمايـة ممثلي العمال في المؤسســة و التسهيلات المنوحة ل لهم.

4) دسنور 23 فيفري 1989.

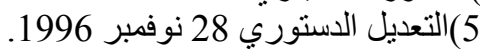

6) القانون رقم 14-14 المؤرخ في 2 جو فوان 1990 و و الخاص بأحكام ممارسة الحق النقابي المعدل

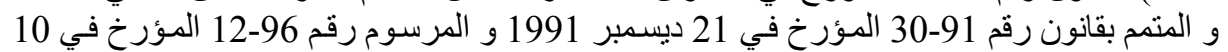
جوان 1996.

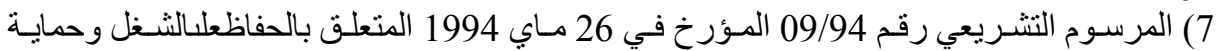
الإجر اء الذين فقدو اعملهم بصفية لاإر ادية ولأسباب اقتصني التصادية.

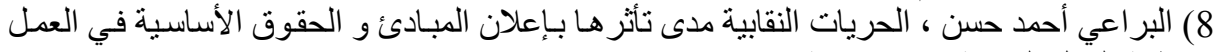

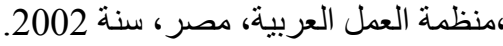

9)عجة الجيلالي، الوجيز في قانون العمل و الحماية الاجتماعية النظرية العامة للقانون في الجزائر ،

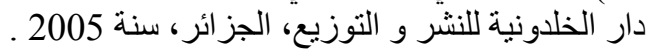

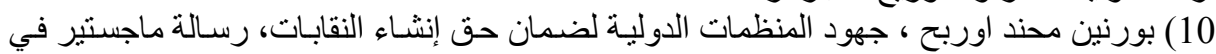

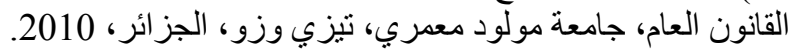

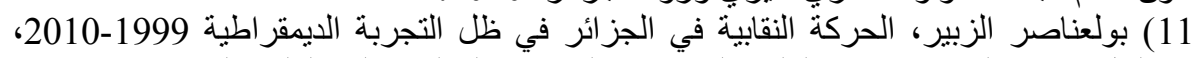
مذكرة لنيل شهادة الماجستير في العلوم السيآسية والعلاقات الدولية، كلية النية العلوم السياسية والاعلام،

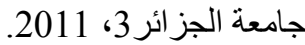

12) قطران حاتم ،اهمية إدماج الحقوق الاقتصادية و الاجتماعبة و الثقافية في الدساتير، شبكة

المنظمات العربية غير الحكومية للتنمية، بيروت البنان الان ،الطبعة الاولى ،ديسمبر ، سنة 2012

13)الفيدر الية الدولية لحقوق الانسان، الجزائر "سوء المعيشة: تقرير عن حالة الحقوق الاقتصادية الإناية

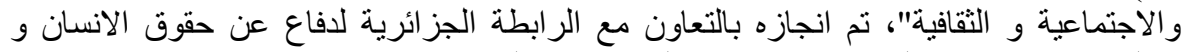

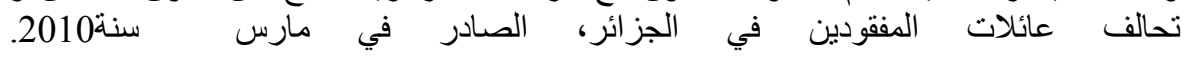
www.fidh.org

14) التقرير الدوري الاول للجز ائر امام لجنة حقوق الانسان العربية ،مارس، سنة 2011.

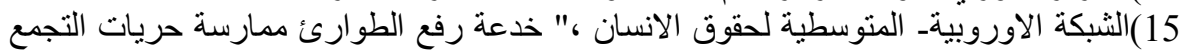

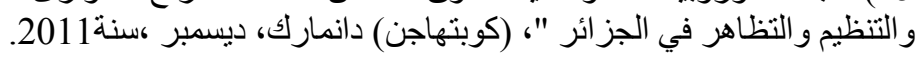

16)الخطوة العمالية نشرة صادرة عن حزب العمال الاشتر اكي ، عدد نوفمبر / ديسمبر 2012.

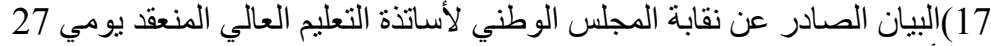
وأفريل18.

18)البيان الصادرعن نقابة المجلس الوطني لأساتذة التعليم العالي المنعقد يوم 11 ماي www.sitevoila.cnes.2006 


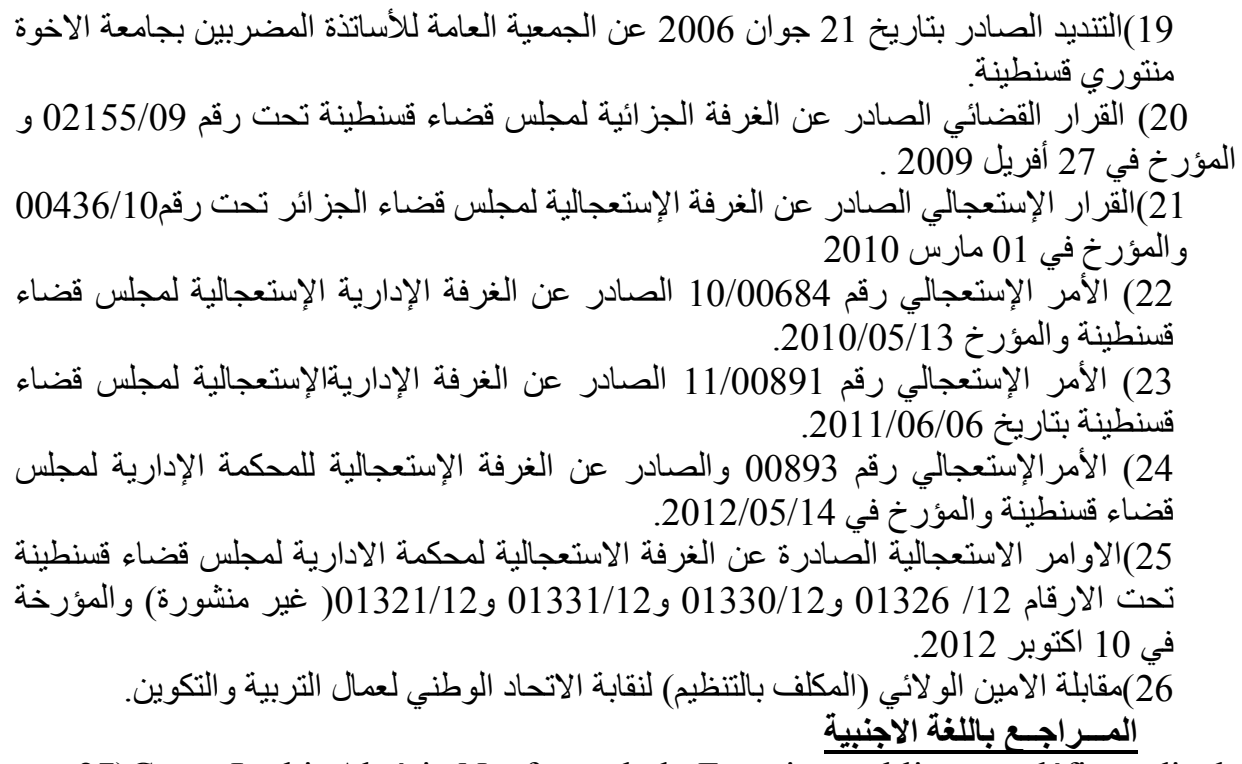

27)Gaïne Larbi, Algérie Naufrage de la Fonction publique et défi syndical, centre de recherches et d'études sur l'Algérie contemporain, édition L'Harmattan, France, 2010.

28)Kattab Sahra, les libertés syndicales en Algérie, dossier $N^{\circ} 8,4$ mai 2004.

www.algérie-tpp.org/tpp/pdf/dosseir-8-libertés-syndicales.pdf

29)Kateb Hakim, Harraoubia rencontre le CNES, les poursuites seront suspendues, Quotidien national la pression 22Mai 2006.

www.lesepressiondz.com/article/2/2006

30)"NASSION BADER, Charbel Farid, coordinateur national adjoint chargé du centre CNES , le CNES n'a pas tenu son 3 éme congre national, 29 Mais Quotidien national, le Maghreb 2007.

www.lemaghred.com/lire.php? $=2537$

31 ) comité national des libertés syndicales, (CNLS), rapport préliminaire du CNLS sur les libertés syndicales en Algérie, libertés syndicales confisqués $\mathrm{N}^{\circ} 01$ avril, ALGERIE, 2005.

www.algerié.watch.org/pdf/pdf-frCNLS-rapport-libertésyndicales.pdf

32)Della Sudda-François, entre répression et manipulation, le courageux combat des syndicats autonomes Algériens, rapport du comité international de soutien au syndicalisme autonome Algérien.

www.cisa-solidaritesyndicats-algérie.org/img/pdf/cisa-situation-syndicatsalgérie-15112009/signepdf

33) Fédération internationale des ligues des droits de l'homme (FIDH), mission d'enquêtes sur les libertés syndicales en Algérie: pluralisme formel et entraves à l'exercice du droit syndical, N³49 décembre 2002. 
www.Fidh.org/magmoyen/rapport/2002/DZ349F1.pdf

34) Déclaration de la rencontre national (2éme rencontre) des sections en grève du 29/06/2006. cnes.site.voila

35) Déclaration de la rencontre national (3éme rencontre) des sections en grève, 14 ET 15 Aout 2006 . cnes.site.voila

36) Communique de solidaires, Mission de l'union syndicale solidaire en Algérie.

www.europe-solidaire.org/spip/php/article13439

37) Communique de solidaires, mission de l'union syndicale solidaires en Algérie rencontre avec le syndicat de la protection civile du snapap.

38) Lettres de l'international des services publics au président Algérien Abdelaziz Bouteflika, Abus des droits fondamentaux de Mr Mourad tchiko, 25/01/2007.

www.Algeria-watcharg/pdf/pdffr/esptchicoo107pdf

39) Lettre du Bureau national (CNES) a l'ensemble des enseignants.

CNES. Voilà net /bureau -national/lettre-ou -auxenseignants-rf.pdf.

40) Message de Chouicha Kaddour, l'un des fondateurs de la coordination des sections du conseil national des enseignants du supérieur, ORAN.

www.cisa-solidaritesyndicats.algerie.org

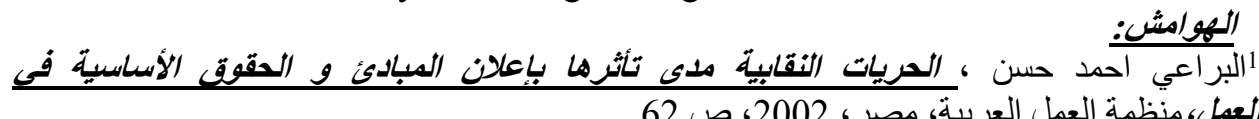

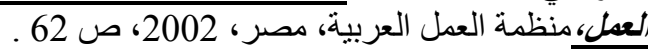

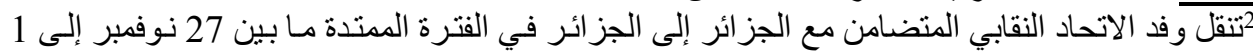

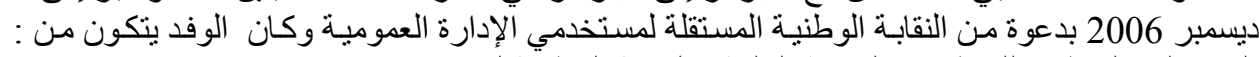

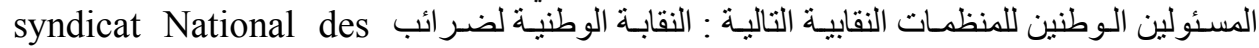

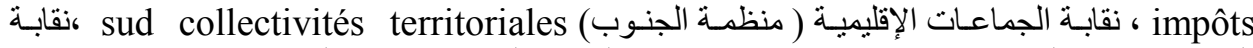
sud pompiers التربية (منطقة الجنوب) sud éducations ،قابة الحمابة المدنية (منطقة الجنوب)

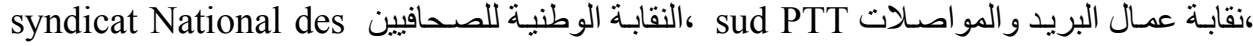
journalistes .

-Communique de solidaires, Mission de l'union syndicale solidaire en Algérie. www.europe-solidaire.org/spip/php/article13439 date de consultation 20/05/2010.

${ }^{3}$ Della Sudda-François, entre répression et manipulation, le courageux combat des syndicats autonomes Algériens, rapport du comité international de soutien au syndicalisme autonome Algérien, p 6.

www.cisa-solidaritesyndicats-algérie.org/img/pdf/cisa-situation-syndicatsalgérie-15112009/signepdf

date de consultation 20/05/2009.

${ }^{4}$ Della Sudda-François, entre répression et manipulation, le courageux combat des syndicats autonomes Algériens, op cité,p6.

${ }^{5} \underline{\text { Ibid,p6 et }} 7$. 
${ }^{6}$ Gaïne Larbi, Algérie Naufrage de la Fonction publique et défi syndical, centre de recherches et d'études sur l'Algérie contemporain, édition L'Harmattan, France, 2010, p 38.

${ }^{7}$ Gaïne Larbi, Algérie Naufrage de la Fonction publique et défi syndicalop cité, p 39.

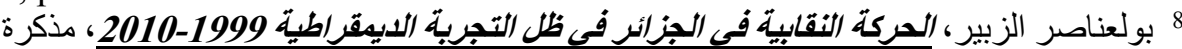

$$
\begin{aligned}
& \text { لنيل شهادة الماجستير في العلوم السياسية و العلاقات الدولية، كلية الية العلوم السياسية و الاعلية العلام، جامعة } \\
& \text { الجز ائر 3، 2011،صاد الياجير في } 126 .
\end{aligned}
$$

9 البيان الصادر عن المجلس الوطني لأساتذة التعليم العالي المنعقد يومي 27 و 28 أفريل 2006 ـ.

www.sitevoila.cnes

Date de consultation 20/06/2006

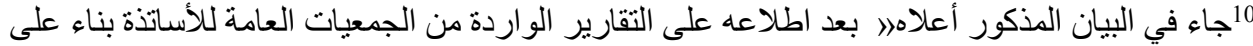

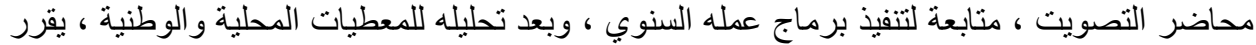

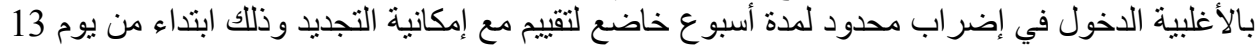

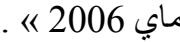

${ }^{11}$ Lettre du Bureau national (cnes) à l'ensemble des enseignants, $\mathrm{p} 2$. cnes. Voilà net /bureau -national/lettre - ou -auxenseignants-rf.pdf. Date de consultation 20/05/2007.

$$
12 \text { البيان الصادر عن المجلس الوطني لأساتذة التعليم العالي بتاريخ } 11 \text { ماي } 2006 \text { ، المرجع السابق. }
$$

${ }^{13}$ Hakim Kateb, Harraoubia rencontre le CNES, les poursuites seront suspendues, 22Mai 2006, p 7 .

www.lesepressiondz.com/article/2/2006 date de consultation 222/05/2007 .

$$
\begin{aligned}
& \text { 14تتمثل الفروع النقابية السبعة عثر في: }
\end{aligned}
$$

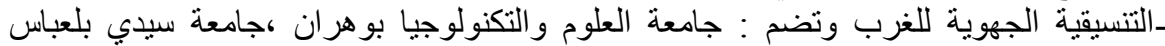

$$
\begin{aligned}
& \text { كامعة تيارت . ل }
\end{aligned}
$$
Www.sitevoila.cnes date de consultation 20/06/2006

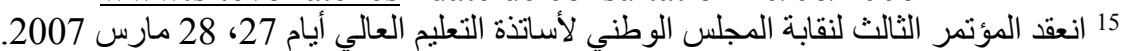

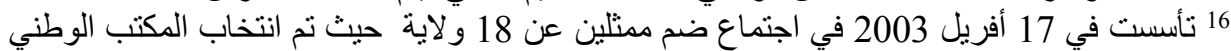

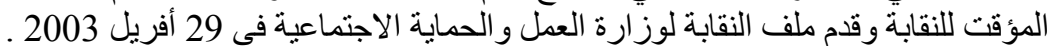
www.CNAPEST.com. Date de consultation 20/05/2005.

${ }^{17}$ Graïne LARBI, Algérie naufrage de la fonction publique et syndical, entretien avec Noura Larbi secrétaire général du CNAPEST,op cité, p 171.

${ }^{18}$ Graïne LARBI, Algérie naufrage de la fonction publique et syndical, entretien avec Noura Larbi secrétaire général du CNAPEST,op cité, p 85. 
${ }^{19}$ Graïne LARBI, Algérie naufrage de la fonction publique et syndical, entretien avec Noura Larbi secrétaire général du CNAPEST,op cité, p89.

20 السيد الطيب لوح عين وزير العدل حافظ الاختام في ماي 2013، وماز ال يتقلد نفس المنصب في

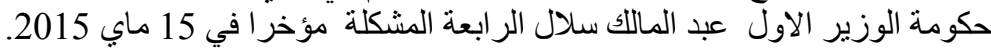

${ }^{21}$ Della Sudda -François, entre répression et manipulation, le courageux combat des syndicats autonomes Algériens, op cité, $\mathrm{p} 8$ et 9.

${ }^{22}$ Graïne Larbi, Algérie naufrage de la fonction publique et défi syndical, entretien avec Mohamed Salem Sadali secrétaire général du syndicat autonome des travailleurs de l'éducation et de la formation SATEF, 0p cité, 110-111.

23/الفيدر الية الدولية لحقوق الانسان، الجزائر "سوء المعيشة : تقرير عن حالة الحقوق الاقتصادية

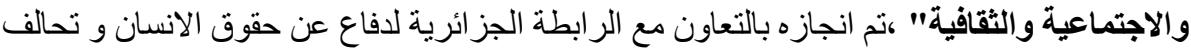

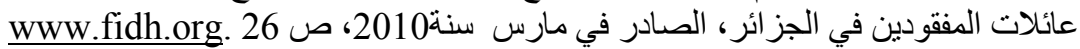

${ }^{24}$ Kettab Sahra, les violations des libertés syndicales, dossier n 8,4 mai 2004, p 13.

www.algérie-tpp.org/tpp/pdf/dosseir-8-libertés-syndicales.pdfdate

de consultation 26 octobre 2006.

${ }^{25} \mathrm{Kettab}$ Sahra, les violations des libertés syndicales, op cité, $\mathrm{p} 13$.

${ }^{26}$ Fédération internationale des ligues des droits de l'homme (FIDH), mission d'enquêtes sur les libertés syndicales en Algérie: "pluralisme formel et entraves à l'exercice du droit syndical $», N^{\circ} 349$ décembre 2002, p14.

27 بولعناصر الزبير، اللحركة النقابية فى الجزائر فى ظل التجرية الديبقراطية 1999-2010، المرجع

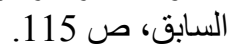

${ }^{28}$ Rapport Fédération internationale des ligues des droits de l'homme (FIDH), mission d'enquêtes sur les libertés syndicales en Algérie: «pluralisme formel et entraves à l'exercice du droit syndical », op cité p14.

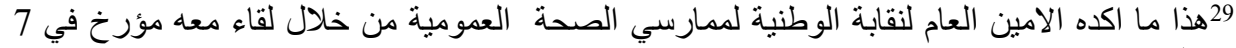

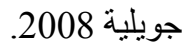

${ }^{30} \mathrm{Graine}$ Larbi, Algérie naufrage de la fonction publique et syndical, $0 \mathrm{p}$ cité, $\mathrm{p}$ 44.

منخرطاكل عضو نقابة يشارك سنويا بـ 80 دج ومتوسط عدد الاشتر اكات يتراوح ما بين 30.000 ـ و 50.000 و 40.000

${ }^{31}$ Graine Larbi, Algérie naufrage de la fonction publique et syndical, $0 \mathrm{p}$ cité, p96.

$$
\text { ـ لدى نقابة } 64.000 \text { مشترك وكل واحد بدفع 200 د دج سنويا. }
$$

${ }^{32}$ Graine Larbi, Algérie naufrage de la fonction publique et syndical, $0 \mathrm{p}$ cité, $\mathrm{p}$ 97.

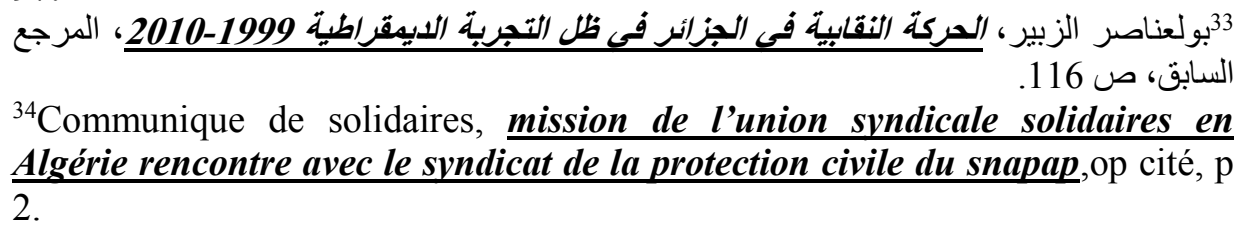


${ }_{35}$ Communique de solidaires, mission de l'union syndicale solidaires en Algérie rencontre avec le syndicat de la protection civile du snapap, op cité, $\mathrm{p}$ 2.

${ }^{36}$ Ibid, p 2.

${ }^{37}$ Déclaration de la rencontre national (2éme rencontre) des sections en grève du 29/06/2006.

cnes.site.voilà date de consultation 20/07/2006.

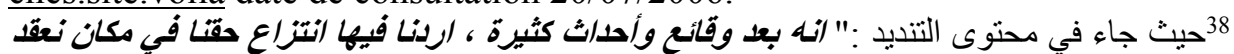

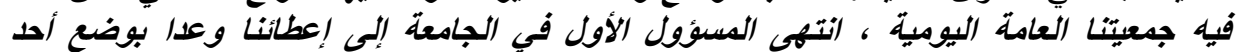

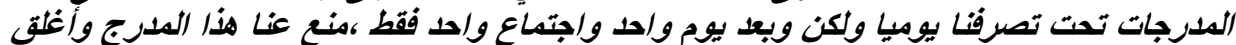

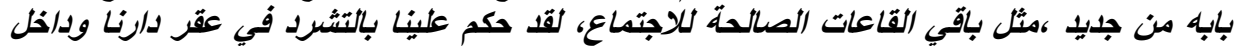

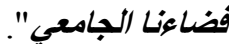
ـالتنديد الصادر بتاريخ 21 جوان 2006 عن الجمعية العامة للأساتذة المضربين بجامعة منتوري

${ }^{39}$ Message Kaddour Chouicha, l'un des fondateurs de la coordination des sections du conseil national des enseignants du supérieur, ORAN. , p3.www.cisa-solidaritesyndicats.algerie.org

$$
40 \text { السلطات الجزائرية تغلق مقر دار النقابات } 26 \text { ماب } 2010 \text {. }
$$

www.ctvws.com/labour-maivement/default.aspx?item=488

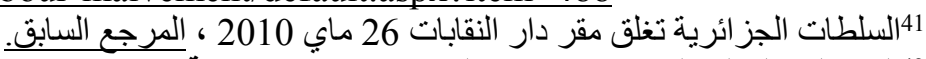

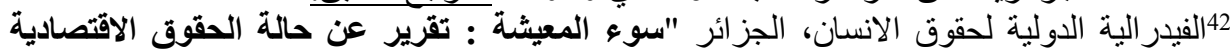

والاجتماعية و الثقافية"، المرجعالسابقص الانصان الجز 29.

${ }^{43}$ Comité national des libertés syndicales, op cité, p 13.

444الفيدر الية الدولية لحقوق الانسان، الجزائر "سوء المعيشة : تقرير عن حالة الحقوق الاقتصادية

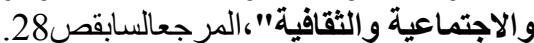

${ }^{45}$ Rapport du comité National des libertés syndicales (CNLS),op cité, p 11.

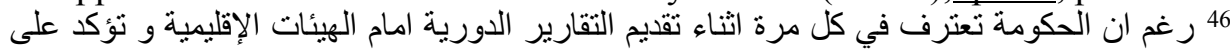

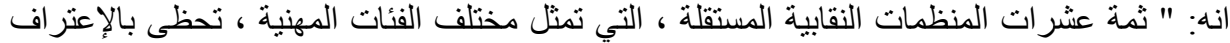

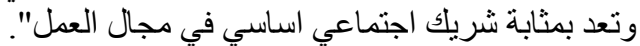

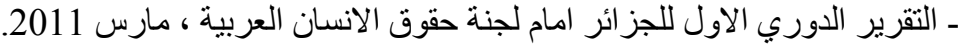

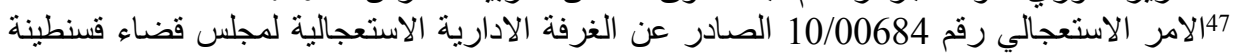

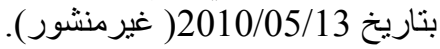

48الامر الاستعجالي رقم 10/00684 الصنادر عن الغرفة الادارية الاستعجالية لمجلس قضاء قسنطينة

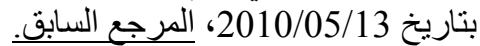

بوالامر الاستعجالي رقم 10/00684 الصادر عن الغرفة الادارية الاستعجالية لمجلس قضاء قسنطينة

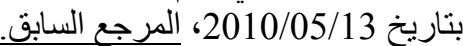

لاريخ الامر الاستعجالي رقم 11/00891 الصادر عن الغرفة الادارية الاستعجالية لمجلس قضاء قسنطينة بتاريخ الآن الاسر الاستعالي (غير منشور ).

51 الامر الاستعجالي رقم 11/00891 الصادر عن الغرفة الادارية الاستعجالية لمجلس قضاء قسنطينة

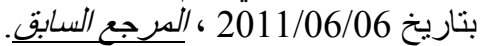

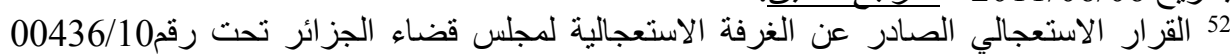
المؤرخ في 01 مارس 2010(غير منشور ). 
Ww Date de consultation20/03/2011.

154/الامر الاستعجالي الصادر عن الغرفة الاستعالية لمحكمة الادارية لمجلس قضاء قسنطينة تحت رقم

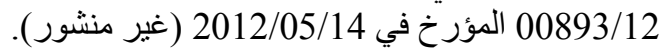

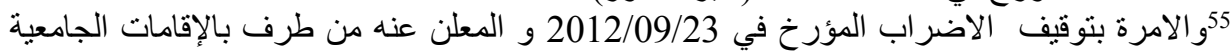

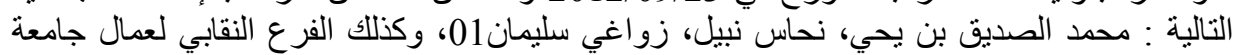

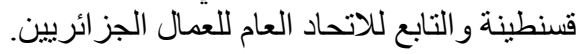

${ }^{56}$ Rapport du comité National des libertés syndicales (CNLS),op cité, p13 et 14. 57الفيدرالية الدولية لحقوق الانسان، الجزائر 'لسوء المعيشة : تقرير عن حالة الحقوق الاقتصادية

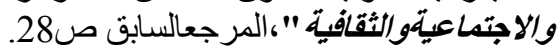

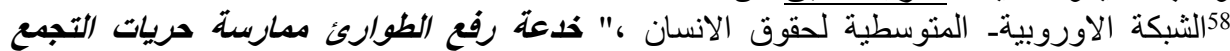

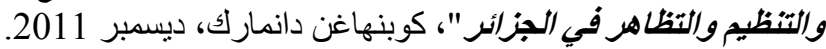

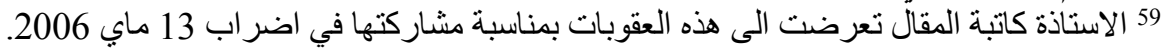
${ }^{60}$ Lettre de l'international des services publics au président Algérien Abdelaziz Bouteflika, Abus des droits fondamentaux de Mr Mourad tchiko, 25/01/2007. www.Algeria-watcharg/pdf/pdffr/esptchicoo107pdf date de consultation 20/09/2008.

${ }^{61}$ Comité international de soutien au syndicalisme autonome Algérien, solidarité avec le Militant syndicale Mr Mourad Tchiko privé de passeport, 18/06/2010.

62 الفيدرالية الدولية لحقوق الانسان، الجزائر "سوء المعيثة : تقرير عن حالة الحقوق الاقتصادية

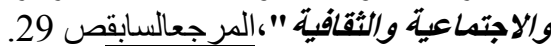
636الثبكة الاوروبية- المتوسطية لحقوق الانسان ، "خدعة رفع الطوارئ ممارسة حريات التجمع والتنظيم والتظاهر في الجزائر" ، المرجية الإنع السابق.

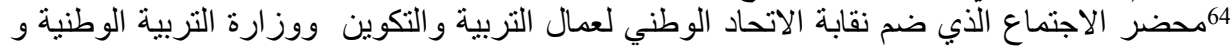

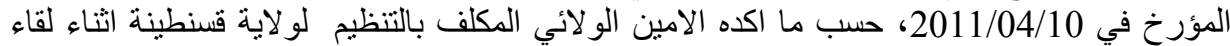

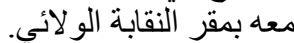

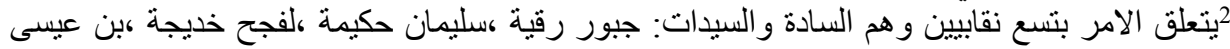

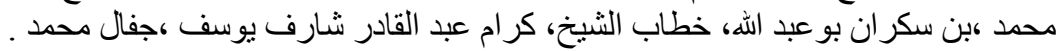

-Kettabe Sahara,les violations des libertés syndicales, op cité, p 12

${ }^{65}$ Kettabe Sahara, les violations des libertés syndicales , op cité, $\mathrm{p} 12$.

${ }^{66}$ Ibid, p12.

${ }^{67}$ Déclaration de la coordination national des sections CNES 14 et 15 Aout 2006, op cité, p 1.

${ }^{68}$ Déclaration de la coordination nationale des sections CNES, 29/06/2006, op cité, p2.

${ }^{69}$ LAMRIBEN HOCINE, six enseignants syndicalistes du CNAPEST devant le tribunal le 17 juin 2007.

يتعلق الامر بكل من السادة :نوار العربي (المنسق الوطني الحالي)، زبير عبد الوهاب ،محفي أرزقي ، قاسمي يوسف ،علي لمدني.

${ }^{70}$ Graïne LARBI, Algérie naufrage de la fonction publique et syndical, entretien avec Noura Larbi secrétaire général du CNAPEST,0p cité, p98. 
${ }^{71}$ Ibid, p99.

${ }^{72}$ Lamriben Hocine, op cité, p2.

73 حسب ما صر ح به المنسق الو لائي لنقابة المجلس الوطني المستقل لمستخدمي التدريس ثلاثي الاطوار اللتربية ،المجلس الوطني المستقل لأساتذة التعليم الثانوي و التقنتي سابقا وذللك خلال مقابلة معه بمقر النقابة النقائ

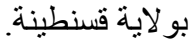

74 تمت متابعة خمسة عشر عضو ا في نقابة المجلس الوطني المستقل لمستخدمي التدريس ثلاثي الاطوار

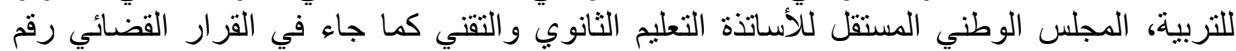

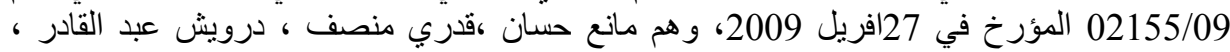

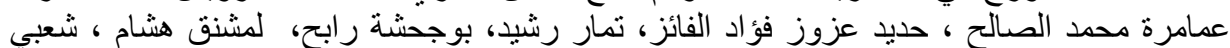

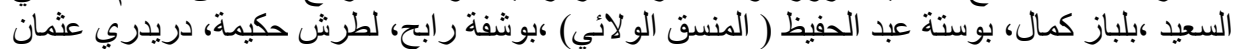

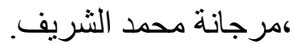
لقار القرار القضائي الصادر عن الغرفة الجزائية لمجلس قضاء قسنطينة تحت رقم 02155/09 و المؤرخ في 27 أفريل 2009 م(غير منشور ). 76 القرار القضائي الصادر عن الغرفة الجزائية لمجلس قضاء قسنطينة تحت رقم 02155/09 و

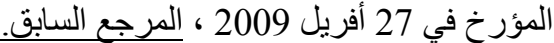
177القرار القضائي الصادر عن الغرفة الجز ائية لمجلس قضاء قسنطينة تحت رقم 02155/09 و المؤرخ

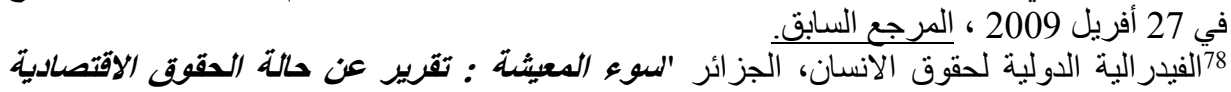

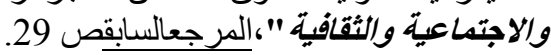

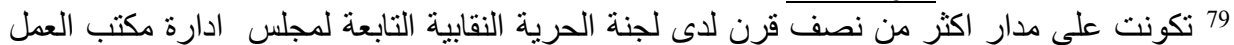

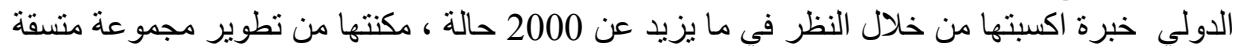

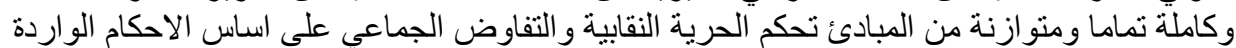

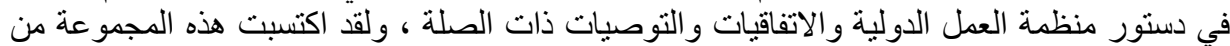

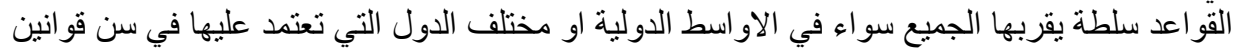

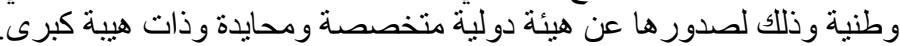

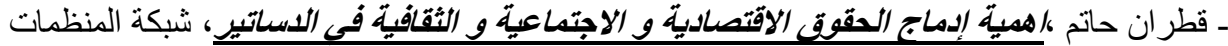

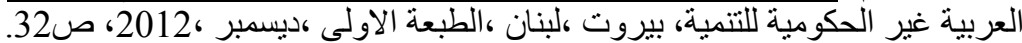
80 قطران حاتم، اهمية إدماجة الحقوق الاقتصادية و الاجتماعية و الثقافية في اللساتير، المرجع

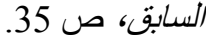
81 بورنين محند اوربح ، جهود المنظمات الدولية لضمان حق انشاء النقابات، المرجع السابق، ص 82 الخطوة العمالية نشرة صادرة عن حزب العمال الاشتراكي ، عدد نوفمبر / ديسمبر 2012 ـ www pst-dz.com 83 الخطوة العمالية نشرة صادرة عن حزب العمال الاشتر اكي، عدد نوفمبر / ديسمبر 2012، المرجع 